\title{
Modifying risk perceptions of Japanese university students using a culturally compatible mode of instruction
}

\author{
Susan F. Walsh \\ West Virginia University
}

Follow this and additional works at: https://researchrepository.wvu.edu/etd

\footnotetext{
Recommended Citation

Walsh, Susan F., "Modifying risk perceptions of Japanese university students using a culturally compatible mode of instruction" (1999). Graduate Theses, Dissertations, and Problem Reports. 3674.

https://researchrepository.wvu.edu/etd/3674

This Dissertation is protected by copyright and/or related rights. It has been brought to you by the The Research Repository @ WVU with permission from the rights-holder(s). You are free to use this Dissertation in any way that is permitted by the copyright and related rights legislation that applies to your use. For other uses you must obtain permission from the rights-holder(s) directly, unless additional rights are indicated by a Creative Commons license in the record and/ or on the work itself. This Dissertation has been accepted for inclusion in WVU Graduate Theses, Dissertations, and Problem Reports collection by an authorized administrator of The Research Repository @ WVU. For more information, please contact researchrepository@mail.wvu.edu.
} 


\title{
MODIFYING RISK PERCEPTIONS OF JAPANESE UNIVERSITY STUDENTS USING A CULTURALLY COMPATIBLE MODE OF INSTRUCTION
}

\author{
Dissertation submitted to the College of \\ Human Resources and Education \\ In partial fulfillment of the requirements \\ for the degree of
}

\author{
Doctor of Education \\ in Curriculum and Instruction \\ Ardeth M. Deay, Ph.D., Chair \\ Samuel F. Stack, Jr., Ph.D. \\ Jurgen E. Schlunk, Ph.D. \\ R. Jerrald Shive, Ed.D. \\ Ranjit K. Majumder, Ph.D. \\ Department of Curriculum and Instruction \\ Morgantown, West Virginia \\ 1999
}

Keywords: Japanese University Students, Comic Book, Manga, College Safety

Copyright 1999 Susan F. Walsh 


\title{
Abstract \\ Modifying Risk Perception of Japanese University Students Using a Culturally Compatible Mode of Instruction
}

\author{
Susan F. Walsh \\ Japanese university students who come to the United States present a particular \\ challenge to universities to teach them about their risks to personal property. The usual \\ method of delivering this message, a lecture during the orientation period, may not be the \\ most effective way of presenting the information due to their limitations in understanding \\ English. It was hypothesized that a manga, or comic book, would be an effective and \\ culturally compatible mode of instruction. \\ A manga was developed and was tested on a group of incoming Japanese \\ freshmen. Forty students (12 females, 28 males) were divided into two groups. One group \\ received instruction through a lecture; the other received the manga. An instrument to \\ test the effectiveness was also developed. Named the Safe Practices on American \\ College Campuses Inventory (SPACCI), it was administered to both groups before and \\ immediately after their respective periods of instruction. It was administered to each \\ group again three months later to determine what the students retained. \\ Analyses of variations were done on the data and revealed that the manga group \\ scored significantly higher $(\mathrm{p}<.05)$ on the inventory than the lecture group, indicating the \\ effectiveness of this method for the short term. In addition, analyses revealed that there \\ was no signiicant difference between the answers of male and female students, nor \\ between students from rural and urban areas. Although the manga group initially scored \\ higher than the lecture group, they did not retain the information any better after three \\ months. \\ The data suggests that a comic book is an effective method of instructing \\ Japanese university students during their orientation period about behaviors that will \\ safeguard their personal property.
}




\section{Dedication}

With respect for Masaichi and Meiko Hattori, the parents of Yoshihiro Hattori, who courageously used the tragedy of the death of their son to try to prevent other gun tragedies in the United States

$$
\text { and }
$$

to my family whose patience and faith saw me through this endeavor. 


\section{Acknowledgements}

I would like to express my deep appreciation to my academic advisor, Dr. Ardeth Deay, whose patient support encouraged me to face the challenges and complete the requirements of the doctoral program.

I would also like to acknowledge the help and support of Dr. Ranjit Majumder, who advised me and saw me through the rigors of the statistical portion of this dissertation.

I also acknowledge with appreciation the other members of my doctoral committee who showed great support and help during this process.

All my efforts would have been pointless without the participation of students, faculty, and staff at Salem-Teikyo University. Special appreciation is due to the faculty and staff who served on the panel of experts: Dr. Gaby van der Giessen, Dr. Carl Frasure, Dr. Catherine Phee, and John Folsom. Additionally, I would like to acknowledge the efforts of the focus group of students: Mayumi Shionoya, Jonathan Schmidt, Trisha Tyler, Ryoko Utsumi, Ryoko Sato, Takeshi Inoue, and Yasuhiro Shikahama. I particularly mention Yasuhiro Shikahama with gratitude, as he served as a translator and mentor of Japanese culture.

Finally, I wish to express my appreciation to my family: my husband and four children who unfailingly provided the love, support and encouragement that saw me through this long process. 
Table of Contents

TITLE PAGE

ABSTRACT

DEDICATION

ACKNOWLEDGEMENTS

TABLE OF CONTENTS

LIST OF TABLES

LIST OF FIGURES

CHAPTER 1: INTRODUCTION

Statement of the Problem

Specific Research Objectives

Importance of This Study

Definition of Important Terms

Limitations

Basic Assumptions

CHAPTER 2: REVIEW OF THE RELATED LITERATURE

Introduction

Cultural Differences

Risk Perception Related to Campus Safety

Factors Contributing to Effective Teaching

Cultural Considerations

Use of Illustrations in Instruction

Use of Manga as Instructional Material (1) ii

Production of the Instructional Material 10

Audience Analysis $\quad 10$

Material Analysis: Determining Objectives $\quad 11$

Sequencing 11

Revisions $\quad 11$

Evaluation 11

Summary of the Review of the Related Literature 12

CHAPTER 3: METHODOLOGY

Introduction $\quad 13$

Developing the Instructional Material 13

Setting Goals 13

Expert Panel 13

Incidence Reports $\quad 14$

Focus Group Data $\quad 15$

Determining Objectives $\quad 15$

Production of Instructional Material 17 
Developing the Inventory 18

Description of the Inventory 18

Validity 19

Translating the Inventory 19

Reliability 20

Selection of the Participants 20

Procedure for Administrating the Inventory 21

Method of Measurement 21

CHAPTER 4: RESULTS

Introduction 23

Analysis of Parts 1 and 2

Gender 23

Hometown 24

Age 25

Pretest Scores 25

Previous Experiences of the Students 26

Groups and Testing Occasion 26

Analysis of Part 3: Content Analysis of SPACCI 29

CHAPTER 5: DISCUSSION AND CONCLUSIONS

Summary $\quad 32$

Purpose of the study $\quad 32$

Methods $\quad 32$

Data analysis $\quad 32$

Conclusions 33

Implications of the Study $\quad 34$

Implications for Preparation

of Educational Material 34

Implications for Instruction 35

Implications for Safety of Campuses 36

Recommendations for Further Research 37

REFERENCES 40

Appendix A : Questions for the Focus Group 46

Appendix B: Comic Book 47

Appendix C: Safety Practices on American College

Campuses Inventory (in English) 59

Appendix D: Comparison of Objectives and Inventory Questions 61

Appendix E: Sample Letter to Students 64

Appendix F: Results of the SPACCI 65

$\begin{array}{ll}\text { CURRICULUM VITAE } & 67\end{array}$ 


\section{List of Tables}

Table 1: Data from the Student Right to Know and Campus Security Act of 1990

Table 2: Table of Group Responses by Gender

Table 3: Analysis of Variance for Gender Differences

Table 4: Table of Group by Rural or Urban Hometown

Table 5: ANOVA for Differences of Hometown (Rural/Urban)

Table 6: Analysis of Variance for Age

Table 7: Analysis of Variance for Prescores

Table 8: One-way Analysis of Variance for Difference Score

Table 9: Analysis of Variation on Post Post Tests 


\section{Table of Figures}

Figure 1: Mean difference scores (post-pre) for learning by lecture and comic book approach

Figure 2: Mean and standard deviations for the interaction 28 group (lecture versus manga) by testing occasion (pre versus post) on SPACCI 
Chapter 1: Introduction

Culture moderates all human behavior. This is important to educators because the students who come to their institutions bring particular cultural assumptions that have an impact on their learning and other behavior. Since 1980, the number of Japanese students who have come to American institutions of higher learning has increased at a rapid pace, doubling in one decade (Tanno, Hamazaki, Mogi-Hein, \& Takahashi,1995). Their cultural assumptions are very different from the culture they will experience here. Of particular concern is how their cultural perceptions about the risks to their personal property will affect their behavior at an American university. This is an issue because Japan has had a reputation of being one of the most secure and safety-conscious societies in the world. Statistics bear out the conclusion that personal property is much less vulnerable to crime in Japan than in the United States. According to a 1995 report, the chances of being burglarized were six times greater in the United States than in Japan, and the chances of being robbed were almost 150 times greater in the United States (Kristof, 1995). When Japanese students come to study in the United States, therefore, they may not be prepared to use precautionary behavior that would insure the safety of their possessions. Losing possessions through theft has an enormous emotional impact on students and affects their attitudes towards the host country, the setting of higher education, and perhaps, their desire to continue their studies here. Thus, these issues make it imperative that American colleges instruct their visiting students about appropriate behavior to protect their possessions.

Further complicating the situation for Japanese students is the problem of language. Since many come to the United States without a facility in communicating in English, the instructions that are usually given during orientation programs may not be effective. In addition, a typical method of instructing new students during orientation is a lecture. Slavin (1994) cautions about the limitations of this mode of instruction: "Straight, dry lectures can be boring, and bored students quickly stop paying attention to even the most carefully crafted lesson" (p.275) .

After considering the culture of the Japanese students and their use of printed material to disseminate information, it became apparent that one way to teach these students about personal safety might be a comic book, or manga. Developing this book with concerns for the appropriate use of visual literacy and materials design became part of the focus of this research.

In an intercultural study such as this, a number of disciplines contribute to the understanding of the problem. In particular, anthropology, communication, psychology, and pedagogical research contributed pieces to the whole. However, two areas came to dominate the research: the students and the method. As Fons (1994) notes, "There should be a congruence between the characteristics of the learner and the characteristics of the material" (p.11). Insights related to the characteristics of the learners were gained from studies of Japanese culture and from studies of Risk Perception Theory. Characteristics of the culture helped predict certain behaviors that might be expected from the students. Risk Perception Theory describes why students fail to behave in ways that would reduce their risks (Lenski, 1992). To understand the characteristics of the material, research was done in materials development and design. The result of this part of the research is a manga that attempts to integrate insights from knowledge about the learners and the objectives of the material. 


\section{Statement of the Problem}

This investigation will assess if an illustrated pamphlet, similar to a Japanese manga or comic book, about protecting private property is more effective in changing precautionary behaviors among Japanese freshmen with a limited English proficiency than a lecture on the same material.

\section{Specific Research Objectives}

The following questions have been formulated in order to achieve the purposes of this study:

1. What are the components in developing a culturally compatible mode of instruction for Japanese students to acquire knowledge about protection of personal property in the United States?

2. Can Japanese students with limited English proficiency be motivated to report intentions of more prudent behavior regarding personal property safety issues?

3 . Is there a difference between the reports of intended behavior of students who have been given a lecture about safety issues and students who have received a comic book that describes the same content material as the lecture?

4. Is there a difference in the responses about intended safety behavior between male and female Japanese students?

5. Do Japanese students who identify their hometowns as rural intend to behave differently from those students who identify their hometowns as urban?

\section{Importance of This Study}

As tens of thousands of college-age students come from Japan to study in American institutions, it is important to understand what their expectations are regarding their own safety, because a sense of safety is a prerequisite to a successful academic career (Lenski, 1992). Many studies have concluded that young people in this age category tend to have distorted, unrealistically optimistic perceptions of their invulnerability to risky situations. (Lenski, 1992; Perloff and Fetzer, 1986; Weinstein, 1984). Japanese students may be even more inclined to disregard dangers because they come from a society that has traditionally been a safe environment.

This study will be significant because

1. It will identify Japanese students' self-reported behaviors that put them at risk regarding loss of personal property. These behaviors are determined by differences between the cultures of Japan and the United States.

2. If the comic book format is successful in transmitting information about safety issues and changing behavior, it will provide another tool for educators to use during orientation programs with Japanese students.

3. It will suggest that the format of using an illustrated pamphlet may be an effective way to transmit information to other groups of students who have low English proficiency.

\section{Definition of Important Terms}

Kanji: A type of pictograph writing used in Japan.

Kouhai-senpai: The relationship of mutual expectations between older and younger students. Older students are expected to be mentors, to guide and protect younger students. Younger students are expected to act deferentially towards their seniors. Manga: Japanese comic books used for entertainment and educational purposes. 


\section{Limitations}

An important limitation of this study is that of language. Because all these students are non-native speakers of English, there is always the possibility of misunderstanding due to translation error. In addition, there is a problem peculiar to the cultural-linguistic system of Japan. In that country, language is often used in a nonspecific, high-context way. Samovar and Porter (1991) explain, "High-context communication is that form in which most of the information to be conveyed is contained in the physical context or is internalized within the people who are communicating. Very little is in the coded symbols that form the transmitted message" (p.151) Since the method of surveying the subjects of this study is in a low-context framework, there may be areas in which the subjects do not transmit their complete attitudes. In addition, there is ambiguity in the Japanese language. As Kato (1973) notes, even the distinction between yes and no may be ambiguous. This is a result of the desire to please the other party in the discussion and to avoid conflict. Therefore, a researcher must wonder if the Japanese subject is responding according to his true understanding of his behavior or according to what he believes the researcher wants to hear. To address the concerns about language, the inventory was presented to the students in Japanese, the native language of the participants.

Another limitation of this study is the small number of students who participated in the research. Only 40 students came in April 1998, and of those only 39 completed the inventories. While this incidental sample is small, it does include all the possible student participants.

The students' location presents another limitation. Salem-Teikyo University is a very small institution in a small town. It would not be appropriate to generalize conclusions from this research to a large urban setting. Additionally, the large population of Japanese students at Salem-Teikyo University makes it an unusual setting. Japanese students who attend other institutions where there is a smaller ratio of international to American students may have different responses about safety issues.

Another limitation of this research is the fact that the data are based on students' reports of their intended behavior. According to Fishbein and Ajzen $(1975,1980)$, this is a reasonable basis for data. These researchers conclude that the best single predictor of an individual's behavior is his intention to perform that behavior (p. 369). To encourage the subjects to report their true intentions (rather than what they thought the researcher wanted them to say), the rationale for the research and the use of the data were explained to them orally and in writing in their native language.

\section{Basis Assumptions}

It is assumed that the freshmen who receive instruction using the comic book will recognize this as a valid means of communicating information. Further, it is assumed that the only intervening variable will be the use of a manga as instruction because all other factors will be kept as similar for the two groups as possible. 
Chapter 2: Review of the Related Literature

\section{Introduction}

The literature review for this study has four main sections. First the literature was reviewed to identify the cultural differences that contribute to the behaviors of Japanese university students who come to the United States to study. Another section discusses literature pertaining to campus safety in the United States and risk perceptions of students. The third section considers effective teaching methodologies for Japanese students who have very limited English proficiencies. Finally, the related literature was reviewed to describe the process of designing instructional materials in general and visual materials in particular.

\section{Cultural Differences}

The earliest European visitors to Japan were astounded by the cultural differences that they encountered. Alessandro Valignano, a sixteenth century Jesuit scholar, remarked ". . . it may truly be said that Japan is a world the reverse of Europe; everything is so different and opposite that they are like us in practically nothing" (White, 1995, p.12). Since that time, other scholars have been trying to describe and explain the seeming cultural opposites. There have been many ways to approach this comparison of cultural variation. One of the most promising ways of looking at cultural variations, according to Triandis, Bontempo, Villareal, Asai, and Lucca (1988) is to consider how cultures compare on a scale of individualism-collectivism. This seems to be especially true in the case of the American and Japanese cultures because the two reflect very different values. Triandis et al. describe a collectivist culture as one in which an essential feature is the willingness of an individual to subordinate his personal goals to the goals of some collective, which is usually a stable ingroup, such as the family (p.324). The idea of ingroup may expand, however, to include the classroom, the work force, and eventually the nation. Even when the ingroup makes costly demands, the individual feels a responsibility to be loyal to the group and regard its needs before his own (p.324). Triandis et al. compare this to an individualist culture in which individuals feel free to drop out of the ingroups which make inconvenient demands. Instead of concern for the ingroup, the individual's barometer is his own internal needs and wants. Triandis et al. note that Japan has a long tradition of collectivism while the United States displays high levels of individualism (p.324).

Another way to look at this phenomenon is on the level of personal psychology rather than cultures. Again a differentiation is made between the United States and Japan. According to Markus and Kitayama (1991), in many Western cultures, there is a "faith in the inherent separateness of distinct persons" (p. 226). An individual in an individualist culture construes himseflf as having reference to his own internal repertoire of thoughts, feelings, and actions, rather than to the thoughts, feelings, and actions of others. In contrast, the psychology of many non-Western cultures, including Japan, stresses the connectedness of human beings. The interdependence of an individual to the thoughts, feelings, and actions of others in relationships is emphasized. In these cultures, individual behavior is determined, in large part, by the person's perceptions of the needs of others.

Finally, another dichotomy that shows the difference between the American and 
Japanese culture has been described as the difference in high context-low context cultures (Gudykunst et al.,1996; Hall, 1976). This refers to the ways in which people communicate with one another. Low context cultures use explicit and direct messages in which the meanings are mainly contained in the transmitted message. High context communication involves implicit and indirect messages in which meanings are embedded in nonverbal communication, relationships, or the socio-cultural context. This differentiation relates to the other dichotomies mentioned before. Gudykunst et al. suggest that low context communication is used predominantly by individualistic and independent cultures, such as the United States, while high context communication is a hallmark of interdependent and collectivist cultures such as Japan (p.511).

Thus it is noted that the Japanese and Americans differ on a cultural level, on the level of personal psychology, and in respect to high context-low context communication systems. The implications of these dichotomies are far-reaching because they affect Japanese students' perceptions of deviance and conflict and ways of coping with risks. Triandis et al. (1988) suggest that collectivist cultures encourage conformity because norms are clear and deviant behavior is punished. The most extreme form of punishment is to be excluded from the ingroup. Fenwick (1983) suggests that fear of exclusion from the group is such a strong sanction that it ensures conformity and controls deviancy. Triandis et al. further posit that collectivist cultures display less competition and therefore harmony is more easily achieved. Markus and Kitayama (1991) go beyond these claims and discuss how an individual's self-construal as interdependent (rather than independent) affects even his motivation and emotions. Because people acculturated in an interdependent climate define themselves in relationship to others, self-control becomes very important; the ability to fit in with others is a crucial basis for self-esteem.

Understanding the Japanese as interdependent and collectivist helps explain some aspects of their society. An emphasis on harmony as a societal goal is a long standing part of Japanese culture. The Japanese were influenced strongly by Confucian philosophy that was imported from China in the seventh century A.D.. Part of this philosophy held up harmony as a strong ideal. (Anderson, R. S., 1975; Beauchamp, 1992; OERI, 1987). When Chinese travelers of the seventh century wrote about their impressions of Japan, they wrote that it was a very orderly society, in which there was very little crime. This can be explained in part by the severity of punishment for crime: a thief could be punished by the death of his entire family (Reingold,1992). Thus the interconnection between the individual and the family was an important dynamic reinforced even by the penal system. Japanese themselves are very proud of this tradition of harmony and pride themselves on their public orderliness (Schreiber, 1995). As a result, Japan has gained a reputation of being a very safe country to live in (Fishman and Dinitz, 1995; Reingold, 1992) The reasons for this apparent safety are many. One is the fact that harmony and avoidance of conflict are valued highly. Teaching how to get along with one's peers is one of the most important goals of early education. Beginning in kindergarten, students are taught to look to their group for approval and to shun activities that would earn the group's disapproval. Teachers do not mediate discipline problems so much as they allow the han, or class group, to determine the outcomes of discipline (Lewis, 1984). As students grow older, they participate in a hierarchical structure of senior-junior ranking known as senpai-kohai. White (1995) suggests that this social structure (which also characterizes relationships in the university and work arenas) is another reason for the 
lack of conflict and crime in Japan; it is a peer-based mechanism of control.

That a peer-based mechanism of control could be a deterrent to crime is supported by a 1983 book by Freida Adler, Nations Not Obsessed with Crime. Adler tested 47 variables for public safety and discovered that the one variable that accounted for safety in all ten of the safe countries was a strong social system with a high degree of integration that communicated shared norms.

Others offer different reasons for the safety of Japanese society. Schreiber (1995) mentions that in addition to deep-rooted family ties, the Japanese have a strong tradition of obedience to authority. One indication of this is the immense public support for Japan's justice system. Often cited in this regard is the prestige and power of the Japanese police (Chang, 1988; Fishman and Dinitz, 1995; Hoopes, 1992; Reingold, 1992). Japan's police are well-educated and have much greater discretionary powers than American police. They work from koban, small police boxes, in the neighborhoods they serve; once a year the police call upon every household to determine who lives there, what their occupations are, and other basic data. As a result, the police are very familiar with the people they serve and even act as social referral agents. Finally, another reason for the safe conditions in Japan, which is often cited by Japanese sources as well as American, is the fact that guns are strictly controlled in Japan (Chang, 1988; Fishman and Dinitz, 1995; Head, 1995; Reingold, 1992; Sanger, 1995; Schreiber, 1995).

The result of these cultural differences is that Japan is one of the few countries in the industrialized world in which one can walk down the road at night and not feel afraid (Fishman and Dinitz, 1995; Reingold, 1992). The population of the United States is a little more than twice that of Japan, but the number of murders in the United States is about ten times as great and the number of robberies is almost 150 times as great (Kristof, 1995). Since robbery is not a common occurrence, it is not unusual for Japanese people to carry large amounts of cash on their persons. One businessman is reported to have said "I feel very lonely if I have less than one million yen $(\$ 10,000)$ in my pocket" (Pollack, 1995). Checks and credit cards are also used less frequently than they are in the United States, Pollack reports. Despite this reliance on cash, muggings are uncommon. Another indication of popular trust is the custom of sending money through the mail in specially marked envelopes.

The Japanese government has recognized that the safety Japanese people feel regarding their property is a disadvantage when they travel abroad. The Ministry of Transport published a booklet to teach Japanese citizens the phrases "Freeze!", "Back off!" , and "Hands up!", in order to prepare them for travel in the United States (Schreiber, 1995) . Another strategy was suggested by a major Tokyo newspaper which recommended that American institutions of higher learning should assume responsibility for the personal safety of their foreign students (A gun tragedy, 1995). While American institutions have moved away from the concept of in loco parentis, paternalism in Japanese universities is a norm, Beauchamp (1992) suggests; Japanese schools are expected to look out for the physical and moral welfare of their students.

Another factor protecting students in Japanese schools is the tradition of hierarchical relations. Junior students, or kohai, can look to their senior students, or senpai, to help them out with social, academic, and safety issues. (White, 1995) Thus, in addition to the problem of coming from a safe society with different cultural traditions about property, Japanese university freshmen may also have very different expectations 
about the support they will receive from their administration and fellow students.

Risk Perception Related to Campus Safety

Risk perception theory investigates how perceptions, beliefs, and knowledge modify behavior. There is a recognition that individuals may not use precautionary behavior to avoid victimization because they underestimate their vulnerability to risks (Davis, 1995; Lenski, 1992; Perloff and Fetzer, 1986; Weinstein, 1984). Kleinhesselink and Rosa (1991) have questioned the role of culture in these perceptions. They asked whether risks are "perceived similarly because of common information-processing strategies, or differently as a result of the deep influences of culture" (p. 13). Building on research done comparing perceptions of populations in Hungary, Norway, and Hong Kong, these two researchers looked at differences between Americans and Japanese. While they discovered some similarities among the populations, they concluded that "... people living in different cultures may differ in their risk perceptions, attributable not only to perceptual biases, but also because they live in objectively different risk environments" (p. 23). As an example of an objectively different risk environment, they mention that crime was dreaded much more by the Americans in their study because of the greater rate of crime in the United States.

Another aspect of the perception of risk involves an asymmetry between perceptions and the realities of crime. That is, people (in both Japan and the United States) who are most afraid of crime are often the ones who are least likely to experience it. (Ito, 1993). Conversely, those who are more lkely to become a victim may not perceive their risk as a serious problem. This is especially true of adolescents, for whom the "It can't happen to me" syndrome is often operative. De la Rue and Rubach (1987) note that ". . . people who have not been victimized by negative life events such as serious illness, accident, or crime tend to perceive themselves as less vulnerable to victimization than others" (p.3). Perloff and Fetzer (1986) explain that people who have never been victimized often underestimate their own vulnerability to victimization. The college students in their study compared their own risk against a vague other "average college student", and concluded that they themselves were less likely to experience a negative life event. The researchers call this perception "the illusion of unique invulnerability" (p.502). Weinstein (1984) explains that people tend to use separate mental compartments to think about their behavior and vulnerability; as a result, peopleespecially young people-underestimate their risks (p.455). If it is true that young people have an unrealistic sense of invulnerability because they do not recognize a relationship between their behavior and risks, and that those who have not experienced victimization feel themselves to be less vulnerable, then Japanese university students would seem to suffer from a double hazard: their youth and the traditional safety of their society do not afford them the experience of coping with risk. They have not developed what some might call "street smarts".

The issue of safety on American campuses has been documented in recent years. In 1993, colleges and universities receiving federal aid were required, under the "Student Right to Know and Campus Security Act" of 1990, to report the number of crimes committed on their campuses. In the first year of reporting, there were 7,500 violent crimes reported, including thirty murders, nearly 1,000 rapes, and over 1,800 robberies. The violent crime numbers were overwhelmed by the number of property loss crimes: over 32,000 burglaries and nearly 9,000 motor vehicle thefts (Lederman, 1993, p. A32). 
However, even these statistics do not give a complete picture of the status of crime on campuses, according to Dave Storm, the Assistant Vice-president for Safety and Environmental Services at Penn State University, who explains that there is no reporting category for larcenies, which account for over $75 \%$ of all crimes committed on campuses (Lederman, 1993, p. A33). Thus the picture of crime on American campuses, especially crimes against private property, looks very different from the safety that presumably most Japanese students have come to expect in their home country.

The issue of campus safety has become an important one for educators and administrators. As Steven Dillingham remarks, “. . . crimes at school disrupt education and may have longer lasting effects on society than crimes committed elsewhere" (Bastion and Taylor, 1991, p. 6). Mary and Eldridge Roark (1987) write, " Violence ... is particularly distressing on campuses in light of institutional commitments to the education, development, and personal safety of individuals. Violence. . is the antithesis of student development; it damages persons and institutions, sometimes in irreparable ways" (p. 2). The need for safety is a prime concern for all people (Maslow, 1970), but it becomes especially important for the foreign student who is simultaneously coping with

so many other stressors as he begins his academic career in the United States.

\section{Factors Contributing to Effective Teaching}

A review of the literature related to teaching Japanese LEP (Limited English

Proficiency) students suggests three areas of concern to this particular research. The first is some culturally-imposed barriers to acquiring an understanding of English. The second is the use of illustrations in instruction. Finally is the use of manga for educational purposes.

\section{Cultural Considerations}

The history of English language instruction in Japan is unique. English has been a required subject for more than a century. In addition, it ranks in a special category as one of the subjects that is tested on the university entrance examinations, insuring its prominence in the anxieties of students who want to continue their education beyond high school. Despite this long tradition of education in English, however, Japanese students consistently test among the lowest on the Test of English as a Foreign Language (TOEFL), which is used by most institutions of higher learning for admissions and placement in their institutions (TOEFL,1997; Tanikawa, 1996). The reasons for the discrepancy between training and language skills are many. Most often cited is the fact that English is taught as an investigative science, more like chemistry, instead of a means of communication. As a result, students may be well grounded in esoteric grammar rules but lack the ability to understand oral English or to produce the language for their own communicative needs (Harasawa,1974; Kimizuka,1977; Lucas,1984).

Another factor working against Japanese students is the lack of similarity between Japanese and English. The Japanese language does not share cognates with English and so has few common base words. In addition, the alphabet is different because Japanese uses three forms of writing: two syllabaries and kanji, a form of pictographs which originated in China. Since the ease with which a target language is acquired is directly related to its similarity to the native language (Kimizuka, 1977), Japanese students seem destined to have myriad problems learning English.

Finally, there is a cultural reason that Japanese students are slower to acquire English than students from other foreign countries. For much of its history, Japan 
repelled the idea of contact with the West. In fact, during the Tokugawa era (1640-1853) the shogunate forbade the building of sea-worthy ships and any Japanese citizen who left the country was forbidden to return, upon sentence of death (Embree, 1939). While these laws changed in the mid-nineteenth century, and Japan made deliberate efforts to understand and imitate the Western world, some attitudes of alienation remain. Masayoshi Harasawa (1974) speculates that the relative geographical isolation of the Japanese may be a factor in this. He also suggests that there is a deeper reason: "The Japanese are unduly addicted to or intoxicated by their own language- so much so that neither English nor any other foreign language can ever succeed in invading their linguistic subconsciousness" (p.76). Lucas (1984) also looked at the difficulties her Japanese ESL (English as a Second Language) students experienced with English and concluded that one reason might be that Japanese people dislike and distrust oral communication (p.595). Whatever the source of the problem, it must be admitted that for at least some Japanese, acquiring a foreign language has had little value. Harasawa (1974) laments the ethnocentrism of his countrymen and claims that some do not really accept the idea that another language besides Japanese is useful for communication. Perhaps this explains why the national tests of English do not emphasize communicative skills. As a result, Japanese students who arrive in the United States with six years or more of English language preparation may not be able to understand spoken English. Use of Illustrations in Instruction

One method for teaching ESL to students with limited English proficiency is to use illustrations or picture books. An illustrated pamphlet, or comic book, may seem like a frivolous vehicle for delivering instructional material, but research shows that illustrations can reinforce written material. A few decades ago, there was a lively controversy about the effectiveness of illustrations on reading comprehension. Some theorists believed that illustrations interfered with reading. S. J. Samuel's conclusion (as cited in Haring \& Fry, 1979), known as the focal attention hypothesis said that pictures did not facilitate comprehension but rather distracted from it (p.185). Other researchers argued that illustrations aided reading comprehension because reading required more than a recognition of orthographic stimuli (i.e., text). For example, Donald (1983) concluded from his research that illustrations increased readers' access to semantic information and therefore assisted reading development (pp. 175-6). Moreover, Goldstein and Underwood (1981, as cited in Donald, 1983) stated that the younger and less competent the reader, the greater the influence that illustrations had. Haring and Fry (1979), confirming research done by Peeck (1974), also found that illustrations facilitated recall of the main ideas of written text. Several studies have also demonstrated that illustrations have been effective in influencing students' emotional reactions (Litcher \& Johnson, 1969; Samuels, 1970).

Another argument for the use of illustrations in instructing students with limited English skills is found in the research of Pierre Wigglesworth (1992). Wigglesworth, an instructor of LEP (Limited English Proficiency) students, concludes that an essential element in teaching these students is "context embeddedness", by which he means providing appropriate contextual clues. Since a comic book uses illustrations, it is one way to provide this context embeddedness.

Ball (1976) traces the use of comic books in the United States, noting that they were originally used to enculturate illiterate immigrants, stating, "The comic strip has 
proven to be an exceptional communicative device. . Assertions have been made that the comic materials reflect and reinforce our social system, affect readers' opinions and attitudes, and provide a vehicle for acculturation for each succeeding generation" (p. 801). In recent years, federal agencies, such as the U.S. Forest Service, the Food and Drug Administration, and the U.S. Department of Agriculture have made use of comic books for educational purposes (Lesko, 1994). An example of an extremely successful Public Service Announcement campaign is the "Take A Bite out of Crime" commercials starring the cartoon character McGruff ( Reid, 1993). Sinatra and Stahl-Gemake (1983) sum up the impact of cartoons by saying, "Today the cartoon is an art form used to make political statements, to sell goods, to demonstrate products and procedures for operating equipment and machinery, to sell public service ideas, to provide information- so many ways that we scarcely notice that we are reading about or watching cartoon figures" ( $\mathrm{p}$. 202).

Use of Manga as Instructional Material

In addition to being used frequently as educational tools in the United States, illustrated books seem appropriate for Japanese students because they are an accepted part of Japanese culture. Schodt (1998) notes that manga, or comic books, are a multibillion dollar industry in Japan, accounting for nearly $40 \%$ of all published books and magazines (p. 69). Not only are comic books ubiquitous, being enjoyed by adult professionals as well as adolescents, but they also are used to inform the public about a variety of topics, such as science, social studies, history, and civics (Barron, 1991; Discover, 1985; Hoopes, 1992; Morton, 1984). Kumagai (1996) states that manga form the core of Japanese youth culture, offering exciting, real-life dramas which are sometimes considered more popular than television. He asserts that manga can "reduce even the most serious economic or political issues to everyday emotional scenarios with which the Japanese youth can easily identify" (p. 74).

\section{Production of the Instructional Material}

Once this form of communicating information was decided upon, it was necessary to look at the literature which addressed how to produce educational materials. Some researchers suggested the advantages of addressing the needs of the audience first; others preferred to consider the material to be taught before the audience was considered. As this research proceeded, it appeared that the two issues developed in tandem, often informing each other. While there was some disagreement about the appropriate first step, there was a consensus about one important feature: there must be congruence between the materials developed and the audience to be taught (Burbank and Pett, 1986 and 1988; Fons, 1994; Gillmore, 1992; Hutton, 1990; Thiagarajan, 1976). A particularly useful model was provided by Gillmore (1992) who developed a comic book to teach adolescents about the risks of AIDS. She outlined the steps her committee used: 1) surveying the population (audience analysis), 2) designing the messages (material analysis), 3) developing preliminary scenarios for the comic (sequencing), 4) revising the content with the help of an advisory committee, 5) writing and illustrating the final design, and 6) evaluating the results of the instruction (pp. 4-7) Each step will be considered in greater detail.

Audience Analysis

Thiagarajan (1976) suggests the need for a learner analysis in order to identify suitable subject matter, to find out what the students already know, to discover student 
experiences in order to incorporate those experiences and interests into the lessons, and to determine the language abilities of the students. She suggests that the best way to make this analysis is by directly observing and interviewing the learners (p. 25). Burbank and Pett (1986) also recommend a familiarity with the skills, knowledge and vocabulary level of the learners (p. 5). Anderson and Tomkins (1983) write

The teacher-author who has produced material initially for his/her own use is usually experienced and well grounded in subject matter and teaching material. $\mathrm{He} / \mathrm{She}$ has an advantage over the non-teacher author because he/she knows problems met by students in the subject area concerned. Materials that are congruent with student needs can be relatively easily produced (p. 51).

A teacher-author is in a good position to do this first step, the learner analysis, and insights from this process will allow the teacher to make more effective material. Material Analysis: Determining Objectives

Once the audience has been determined and the writer is familiar with their skills, the next step in developing educational material is to determine the objectives: what is it that the writer wants the learner to know after using the materials? Thiagarajan (1976) explains that this subject-matter analysis is important because it suggests learning activities, it generates an outline and a suitable sequence, it gives the writer a set of objectives, and it helps the writer construct a way to evaluate the success of the instruction. Gillmore (1992) used this method effectively in developing an instructional comic book to fight AIDS. She first surveyed a large group of adolescents to determine their attitudes and knowledge in the intervention she planned to discuss. The data she collected was used to design messages to reinforce positive beliefs and alter negative ones (p.6). Following this model, this research also surveyed a number of students to determine their attitudes towards personal property crime. From this information, objectives were developed.

Sequencing

The importance of a logical sequencing of ideas is stressed by Burbank and Pett (1988), and Wright and Conroy (1988). It is important to have an organized, logical sequence of ideas and also to have a logical, organized sequential design of the text. Balan (1989) explains the need for considering the text design: "By carefully structuring text and applying verbal and typographical cues, the reader spends less time processing text and more time learning new material"(13). Balan concludes, "Effective text design can improve the instructional quality of print materials by grabbing the attention of readers and helping readers access, process, and recall information" (17).

Revisions

After the author has considered the audience, developed objectives, written the text and illustrated it in a logical, sequential manner, the author should try out the material on a test group, as Gillmore (1992) and Sawicki (1989) did. At this point, revisions can be made, based on the recommendations of the test group. Gillmore's group reviewed the material for content, as well as gender and cultural sensitivity (p. 6). Sawicki (1989) also used a group to provide feedback; their comments and critiques were crucial in developing an appropriate language for his comic book.

$\underline{\text { Evaluation }}$

As the final step, the author will have to develop a way to evaluate the effectiveness of the instructional material. As Reiser and Dick (1996) note, evaluation 
cannot be viewed separately from the instructional process; the assessment must be consistent with the goals and objectives of the instruction (p. 83).

Summary of Review of Related Literature

To summarize, the review of related literature gave insight into the culture shared by the Japanese students. It suggested areas of potential conflict; for example, Japanese students from a cohesive, collectivist, hierarchical society may differ in their expectations of the help they would receive from American universities and police. They may also have different attitudes towards individual rights and responsibilities. Also, the review pointed out Japanese customs that would be inappropriate in the United States, such as carrying large sums of money and sending cash through the mail. Finally, the culture of Japan suggested a teaching tool, the manga, that might be effective and culturally appropriate.

The review of the literature regarding risks on American campuses and Risk Perception Theory indicates that incoming Japanese students do present themselves as a group that needs special attention. There is documented risk to personal property at American institutions of higher education. In addition, the sense of invulnerability felt by some adolescents combined with a naivete about the real dangers of property loss in the United States make Japanese freshmen particularly vulnerable.

Finally, the literature about educational materials indicated that it would be feasible to develop an instructional tool, a manga, to explain precautionary behavior to this vulnerable group. This manga would be a high context tool, in which meaning is embedded in the illustrations, to address the language needs of this particular group of students. Moreover, since comic books are valued in Japan, the manga would be a culturally compatible mode of instruction. 


\section{Chapter 3: Methodology}

\section{Introduction}

This research involved three procedures, which the methodology chapter will discuss. The first consideration was to develop the method of instruction. Goals were set and these became the concepts that would be taught. Then the instructional material, the manga, was developed. After that, the second consideration was to create an instrument to assess the instruction; this was named the Safety Practices on American College Campuses Inventory, or SPACCI. This instrument had to be tested for validity and reliability and translated into Japanese. The last part of the procedure was the administration of the SPACCI to students who had received instruction from the manga or the lecture. While the production of the instructional material and the production of the inventory will be described as separate processes, there were overlaps in their development. The inventory was an outcome of the goals set for the instruction. Also, some of the people who were helpful in setting the goals were also consulted for the inventory. In a sense, the manga and the inventory progressed together.

\section{$\underline{\text { Setting Goals }}$}

\section{Developing the Instructional Material}

The advice of several researchers was to get to know the learners (Burbank and Pett, 1986 and 1988; Fons, 1994; Gillmore, 1992; Hutton, 1990; Thiagarajan, 1976). Therefore, it was decided that the first step in the research would be to ascertain the vulnerability of the Japanese freshmen at Salem-Teikyo University to personal property crimes. There were several sources of information. One was an expert panel of educators familiar with the issues of campus safety. Also, the researcher was given access to the yearly report of campus crimes, which must be filed in compliance with the Student Right to Know and Campus Security Act of 1990. The researcher also consulted a focus group of students who contributed information about their experiences with crime on campus. In addition to the panel, the focus group, and the yearly reports, the researcher's seven years of teaching this group of students contributed the experience of directly observing and interviewing the learners that Thiagarajan recommends.

\section{Expert panel}

This group of advisors consisted of a professor of Criminal Justice, a professor of Special Education, the Dean of Students, and the Director of Security at Salem-Teikyo University. The professor of Criminal Justice has taught Japanese students at the university since the merger of the American and Japanese institutions in 1989. In addition, he has specifically studied the criminal justice systems of the two cultures and has published an article about the Japanese police. The professor of Special Education is a native of Canada and has considerable experience in the comparison of international educational systems. The Director of Security also has worked with the Japanese students since 1989; before he became the Director of Security at Salem-Teikyo University, he served as Chief of Police for the town of Salem, WV for seven years. The Dean of Students has worked closely with the international students and is the one to whom the residence hall directors report incidents of crime on campus. Thus all four of the experts have had extensive experience with international students, especially Japanese students, and are familiar with the personal property and safety issues that exist on the Salem-Teikyo University campus.

The researcher shared with the experts a preliminary list of objectives that were 
based on experience with the students. The experts were asked to evaluate those objectives and add more of their own. They concurred with the original list and made suggestions which were incorporated into the final set of objectives. The Dean of Students pointed out the problem of theft that occurs when students leave doors and cars unlocked. She also pointed out that recovery of stolen goods is hampered by the fact that students do not note the make and serial number of their belongings, so identifying items that are recovered is impossible. The Security Officer noted that most crimes on campus were crimes of opportunity. He also stressed the need to lock doors with a key, explaining that some students thought they had locked their door by pushing in a button; this does not secure the lock on the doors in the residence halls.

Incidence reports.

Every year a report is filed in accordance with the Student Right to Know and Campus Security Act of 1990. Table 1 summarizes the data from three previous years (See Table 1).

Table 1

Data from the Student Right to Know and Campus Security Act of 1990

\begin{tabular}{llll}
\hline & \multicolumn{1}{c}{ Year } & 1996 \\
Homicide & 1994 & 1995 & 0 \\
Sexual Offenses & 0 & 0 & 0 \\
Robbery & 0 & 0 & 0 \\
Felonious Assault & 0 & 0 & 0 \\
Simple Assault & 0 & 0 & 3 \\
Breaking \&Entering & 5 & 5 & 6 \\
Burglary & 11 & 13 & 0 \\
Larceny & 0 & 0 & 21 \\
Motor Vehicle Theft & 18 & 25 & 0
\end{tabular}

It is evident that the largest problem for this campus is in breaking and entering and larcenies. However, as Lederman (1993, p. A33) notes, many crimes are not reported, so the actual number of thefts could be higher. 


\section{Focus group data.}

One way to estimate the severity of crimes that are not reported is through the use of anecdotal data. To do this, the researcher convened a focus group of students. This focus group was comprised of seven students. Two were Americans, a male and a female. They both were upperclassmen who were majoring in the Japanese language and had extensive experience with Japanese culture, including extended stays in that country.

The other five students were Japanese. Two were female; three were male. Two were freshmen; the others were upper classmen. Thus, there was a fairly representative group of Americans and Japanese, male and female, newer and older students. The focus group supported what the statistics indicate about the problem of theft on the campus. When asked if they had personally ever experienced crime in the United States, four of the seven reported theft of money, ranging from a small amount to a thousand dollars. (Coincidentally, one student on the panel experienced the theft of his property a few days after the initial meeting to discuss the problem of crimes on the campus. He hung posters offering a reward for the return of his book bag but never recovered his property.) Four students on the panel said they had not experienced theft personally. However, when they were asked if their friends were victims, all said yes. They reported that friends had lost money, expensive clothing, and video games. One student volunteered that he thought some students felt there was a freedom to victimize naive students.

\section{Determining Objectives}

The next step, after discerning the problems facing the specific audience, was to identify objectives in teaching the Japanese freshmen students about safety. Again, the research was informed by the insights received from a review of the literature about the experiences of students, the panel of experts and the focus group of current students who added their advice. The group of students was especially helpful in advising about issues of safety, their perceptions of the dangers at the university, and the use of a comic book to instruct incoming Japanese freshmen. (See Appendix A for a list of questions posed to this focus group.) A list of objectives for instruction was compiled. The focus group and the expert panel were requested to comment on the objectives and add any that they thought of. The following concepts and accompanying objectives are the result of that process :

1. In the United States, cash is not used as frequently as it is in Japan because there are dangers in carrying large sums of cash.

a. Students should not carry large sums of money on their persons.

b. They should not send cash through the mail.

c. They should not be conspicuous in carrying money.

d. They must learn to use the currency correctly.

This objective was developed because carrying cash is common in Japan. Also, Japanese do send cash through the mail in specially marked envelopes. Two of the upperclassmen in the focus group admitted that they had paid bills in that manner when they first came to the United States. Finally, several students in the focus group urged the researcher to explain the need for prudence in carrying money and in asking someone else to count out change, as they had seen freshmen hold out palms full of money and ask clerks to take the correct amount.

2. Non-cash sources of money (checks, credit cards, bank or ATM cards) are 
convenient but they need to be used carefully.

- Students should always check bills before they sign

them,

check receipts when they receive them, and keep all receipts

because their card number may be on them.

b. Students should protect the security of their Personal Identification Number (PIN).

c. They should keep a list of their credit card numbers in a safe place.

This objective was developed after discussing the problem of lost wallets with the university's Director of Security. It was also formed by an experience of the researcher; three years ago, one of the Japanese students came to his teacher for help. He had deposited thirty ten-thousand yen notes at the bank. However, he did not look at the receipt that the teller gave him. The teller had credited him with depositing thirty thousand-yen notes. It took the bank three weeks to find and acknowledge its mistake. The students in the focus group described similar concerns.

3. Personal possessions need to be protected.

1968 Students should identify all their possessions by putting their names on books, appliances, games, and all other possessions.

1969 They should record the serial numbers of their valuables and give the list to their Residence Assistant (RA).

1970 They should always lock their room door, their car doors, and the door to their residence hall.

d. Students should not leave their valuables where they could be taken.

This objective was especially stressed by the focus group and the panel of experts. The Director of Security noted, "Most crimes are crimes of opportunity." These could be eliminated if students were more careful about taking care of their possessions. This is reflected in the Campus Crime Report for 1996-1997. The largest category of crimes was larceny. The officer also reported that six cars (belonging to students) were broken into since the beginning of 1998. In four cases, the doors were unlocked. Students in the focus group reported that they had frequently seen book bags belonging to Japanese students left in classrooms during the lunch hour; however, they noticed that most American students carried their book bags to lunch with them.

4. Protection and help are available if the students are in trouble, but they are responsible for assisting the authorities.

a. Students need to know how to reach their RA, campus security, and the police.

- The police cannot help if the students are unable to provide identifying numbers, descriptions, etc.

c. Police in the United States do not have as much discretionary power in apprehending criminals as they do in Japan.

1971 An important factor in safety, especially in strange places, is to be with other people.

This objective also came from discussions with students and the expert panel. The security officer stressed that students must understand the limitations of campus police. The older students explained that they had sometimes felt frustrated when the campus 
security personnel were unable to stop crimes from occurring; they came to understand that the security personnel were not authorized to act as the police in Japan. The students themselves suggested that the freshmen be warned about traveling alone, especially at night. While the Campus Crime Report indicates that students do not have much to fear at this university, the students were concerned about freshmen who travel to large cities and do not exercise caution.

Production of Instructional Material

Once the objectives were determined, the next step was to develop a comic book to use as an instructional aid during Orientation. The focus group again gave advice regarding the comic; they agreed that they had enjoyed manga in Japan and they thought that this would be an appropriate way to instruct students. The next phase was to write out a story board, a list of captions and description of illustrations. A professional cartoonist from a local newspaper was engaged to draw the illustrations. The completed manga was then taken back to the focus group for their suggestions and approval. The final product is shown in Appendix B.

There were several considerations in developing the manga: the style of the text, the characters, the layout, the mechanics of the text, and the content of the text. Research informed the process in each step.

When writing instructional material, an author must choose the style of writing. Expository and narrative writing are two possibilities. Dubin and Olshtain (1986) argue for the use of narrative in texts for lower level second-language learners. They explain that the element of chronology, which is universal in narratives, makes this form easier for an inexperienced reader. Also, narratives seem to be common to all literate societies, so even inexperienced readers will feel some familiarity with this rhetorical style (p.151). Therefore, the decision was made that the manga would describe the adventures of two characters in a chronological, narrative style.

The next step was to consider the nature of the characters in the text. Dubin and Olshtain recommend controlling for complexity in four areas: the degree of redundancy, the degree of information given or withheld, the complexity of the characters, and the complexity of the events (p. 151). Since the audience comprises students who are limited in English proficiency, it was decided to make the characters very simple in their representation of two behaviors: Kenji represents prudent, precautionary behavior and Koji represents behavior that is less adapted to the American culture. There is a redundancy in the presentations of the behaviors. Their characters are well-defined and consistent throughout the comic. The consequences of the behaviors are explicit, so students are not required to read between the lines. Finally, the characters and the events are not complicated.

After the characters and situations were developed, the next step was to consider the layout, or placement of the frames on the pages. Hutton (1990) and Balan (1989) indicate that the most important feature of the layout is consistency. Therefore every page has a consistency: Kenji's story is on the left, Koji's is on the right. Kemp and Dayton (1985) indicate that there is a reader preference for a double-column format on a page (p. 20), so this format was followed.

Another important consideration is the placement of the text. In the manga, the text was written directly under each illustration. This follows the advice of Balan (1989) and Burbank and Pett (1988) that the text be placed close to its illustration. These 
researchers also agree that there is no need for right hand justification, as this makes reading more difficult.

Another consideration is the amount of information, visual and text, to place on each page. Kemp and Dayton (1985) maintain that the generous use of white space in printed material makes comprehension easier (p. 20). Therefore, only four frames of illustrations were put on a page.

Finally, the most important advice about layout came from Burbank and Pett (1988) who suggest that visuals should be simple and must reinforce the written text (p. 3). An effort was made to insure that the visuals and text were compatible and the focus group of students was asked to evaluate whether or not this had been achieved.

Once the layout was planned, it was necessary to write the text on the pages. The researcher decided to use legal size paper, to allow room for the generous use of white space, as Kemp and Dayton (1985) recommend. Burbank and Pett (1988) recommend a simple serif or sans serif font and a 9 to 12 point size (pp.8-9) so the manga has been written in Helvetica font, size 12. They state that the optimal length of text is 39 characters, or approximately seven words per line. The text in the manga conforms to this standard. They also recommend a mixture of upper and lower case letters when there are several lines of type. In the manga, they are mixed. Finally, Kemp and Dayton discuss the use of color in printed material and conclude that black and white is as effective for learning as color (p. 19). This also makes the reproduction of the manga easier and less expensive.

After the technical features of the text were selected, the researcher needed to consider the content. It was decided to make the story line as simple as possible, using short, concise statements and active language (Burbank and Pett,1986; Dubin and Olshtain, 1986). Also a section of questions was placed half-way through the text. The rationale for this is research by Balan (1989) that adjunct questions may support the integration process for the learner (p.14). Burbank and Pett (1988) also state that questions keep the audience involved, focus its attention, and facilitate recall of the information (p. 5). Kemp and Dayton (1985) term questions inserted into printed material "motivators", which cause the learners to pay close attention, look for relevant clues, and put forth the effort to learn (p. 19). In addition to the questions, a summary at the end of the text was included, as Balan suggests that summaries aid the recall of salient facts (p. 15).

Description of the Inventory

\section{Developing the Inventory}

The objectives which were developed with the aid of the focus group and expert panel were used to write an inventory which was entitled the "Safety Practices on American College Campuses Inventory", or SPACCI (See Appendix C). For each objective, there is at least one question that will elicit the intention to use or not use precautionary behavior. (See Appendix D for a summary that shows how these objectives were used to form the inventory questions.)

The inventory consisted of three parts. Part 1 asked for biographical data. First it asked the student's gender and age. Then it asked the student to characterize his/her hometown as urban or rural. Then it asked if the student had ever visited the United States before. Finally, the inventory asked whether the student was a new freshman or a transfer student. 
Part 2 of the inventory consisted of twenty-five questions about the students' intended behavior in the realm of safety. The questions elicited the responses "definitely yes", "yes", "no", and "definitely no".

Finally, Part 3 of the inventory asked the students for more information about the subject matter covered in Part 2. For example, Part 2 asked if students intended to carry a lot of money on their persons. Since "a lot of money is a subjective term, Part 3 asked them how much money they felt would be suitable to carry. In addition, there are factual questions to test recall of salient facts, such as the telephone number to call for emergencies.

The pretest, post test, and the post post test versions of the inventory all contain the same questions. All three inventories conclude with an open-ended question that asks the students' suggestions for safety advice. This information will be useful for future revisions of the safety instruction. Validity

The inventory was tested for content validity and reliability. In discussing types of validity, Anastasi (1976) describes content validity as "the systematic examination of the content to determine whether it covers a representative sample of the behavior domain to be measured" (pp. 134-135). She continues by saying that content validity can be built into a test "by the consultation with subject-matter experts" (p. 136). The inventory was tested for content validity by submitting it to an expert panel; this panel consisted of an education professor, a professor of Criminal Justice, the Dean of Students, and the Director of Security at the university. These people were chosen because of their extensive experience with the student population to be surveyed and for their knowledge of safety issues on the campus. Their comments and suggestions were incorporated into the inventory. The expert panel was asked to look at each section of the completed inventory and decide whether it addressed the objectives that had been determined. They could respond that the questions did satisfactorily cover the material, did not address the issues, or were unclear. Anastasi (1976) suggests that content validity permits answers to two questions: 1) does the test cover a representative sample of the specified skills? and 2) is the test performance reasonably free from the influence of irrelevant variables? (p. 138) All four respondents on the expert panel answered that the three sections of the inventory were appropriate to address the issues and goals. In this way, there was $100 \%$ agreement among the members of the expert panel and the content validity was established.

Translating the Inventory

In administering the inventory, it was necessary to translate the instrument into Japanese, the first language of the target population. Brislin, Lonner, and Thorndike (1973) discuss the advantages of using the back-translation method. They note that if a researcher, who does not know the target language, asks a bilingual to translate the questions, the researcher usually cannot judge the accuracy of the translation. Therefore, they recommend that two bilinguals be employed, one translating from the source to the target language, and the second translating back to the source language (pp. 40-41). Brislin, Lonner, and Thorndike further discuss some of the potential problems that can occur even from this method of back-translating. They note:

The bilingual translating from the source to the target may retain many of the grammatical forms of the source. This version would be easy to back-translate 
but worthless for the purpose of asking questions of target-language

monolinguals, since its grammar is that of the source, not the target. (p. 41)

This issue became problematic for the back-translation of the inventory because there is a difference in the way English and Japanese speakers respond to negative questions. In English, agreeing with a negative question requires an affirmative response. For example, in answering the question "Wouldn't you leave your door unlocked if you went to the restroom?", an English speaker would respond, "Yes, I would." In Japanese, the answer to show agreement is "Yes, I would not." The questions on the inventory varied; some required a positive response and some a negative response. As a result, there were some negative questions. When the inventory was administered to the pilot group of upperclassmen, they were confused by their options. In an effort to make the Japanese translation agree with the English grammatical construction, the translator had given them the choice of "Yes, I would" and "No, I would not"; the students wanted to respond "Yes, I would not". The inventory was rewritten to eliminate the confusing negative questions. Brislin, Lonner, and Thorndike recommend another method of translating, the "committee approach" (p. 46). They suggest that this may give the researcher more confidence in the fidelity of the translation. This approach was employed in conjunction with the back-translation method to try to ensure accuracy and avoid confusing grammatical patterns.

Reliability

The next issue was to establish the reliability of the inventory instrument. This was accomplished by administering it to a pilot group of Japanese upperclassmen first. The inventory was administered, in Japanese, to the group of fifteen students. Two days later, it was again administered and the results were correlated. The Pearson productmoment correlation was $\mathrm{r}=0.83$ with a $\mathrm{p}<.01$. This confirmed the reliability of the inventory (Gravetter and Wallnau, 1992).

Selection of Participants

The population for this study was students at Salem-Teikyo University, in Salem, West Virginia. This site is particularly desirable because it has a significant Japanese student population. In 1997, there were approximately 300 Japanese students studying at S-TU. Founded in 1989 by the merger of Salem College and the Teikyo Foundation, the university has a student population that is approximately $40 \%$ Japanese and $60 \%$ American and other nationalities. The new Japanese students entered the university on April 22,1998. April is the month when universities traditionally start classes in Japan. Therefore, to accommodate these students and to allow them to stay in synchrony with their cohorts in Japan, the university has determined that new students from Japan will have Orientation in mid-April and begin their academic studies in May. In 1998, forty new students arrived in April.

All incoming Japanese students participated in the initial inventory. They were divided into two groups; these became the control group, which would receive instruction by a lecture, and the treatment group, which would receive instruction by the manga. There were 20 students in each group. However, one female student chose not to answer parts of her inventory, so the control group had 19 responses while the treatment group had 20.

Permission to inventory the students was obtained through the Human Resource Committee of Salem-Teikyo University and the Institutional Review Board of West 
Virginia University. When students arrive in the United States, they have an on site orientation which lasts approximately two weeks. Faculty and staff usually teach during orientation. The initial inventories were administered during the student orientation program on April 24, 1998, when the students had been in the United States two days. The safety program was taught during this time. The post post test was administered on July 20, approximately one semester after the initial tests.

Procedure for Administering the Inventory

The purpose of the inventory was explained to the students, orally in Japanese, and in written form, again in Japanese. They were assured that their participation was entirely voluntary and that their answers would be used only for the purpose of research to enhance the orientation of international students. (See Appendix E.)

Both the control group and the treatment group received the inventory before their instruction as a pretest to determine their anticipated behaviors regarding safety. Then the first group received instruction about dangers on the American campus by way of a lecture in English, followed by a translation in Japanese. The lecture and the translation followed a script. All of this was done orally. Following the lecture, students were permitted to ask questions. No one did. Then they were asked to answer the inventory again to determine the impact of the instruction. The instruction and two testing sessions (pretest and post test) lasted 90 minutes.

Next the treatment group met. After their pretest, this group was given the manga. In addition to their individual copies of the manga, the students were able to look at the pages which were projected on an overhead projector as the explanation was read. They were given the same lesson on safety as the control group, following the same script. The same Japanese student did the translation. They were also given the opportunity to ask questions, and no one did. Then they took the post test. This session also lasted 90 minutes.

The post post test was administered on July 20 on an occasion when all the students were together for a writing workshop which was part of their ESL class. They were not separated but took the inventory together.

Method of Measurement

Part 2 of the inventory consisted of twenty-five questions that asked students for their intentions regarding precautionary behavior. Every question was worded "Will you ...?" with the remainder of the question describing a particular behavior that either helps or hinders safety. The answers to the questions were consistently posed as a four part Likert scale: "Yes, definitely", "Yes", "No", and "No, definitely". Some of the questions were worded in such a way that the safest answer was "Yes, definitely". Others required a "No, definitely" answer to be the safe reply. After the students answered the inventory questions, the answers were coded; four points were given to the safest response, three to the next safest, two to the next, and one point to the least safe answer. The answers were tabulated and each student's pretest and post test responses were recorded.

The information from parts 1 and 2 of the SPACCI was entered into a computer with a SAS (Statistical Analysis System) 1993 program. Each student was assigned a number from 1-39. The entry was also coded with a number to indicate whether the student was part of the control, or lecture, group (1) or the treatment, or manga, group (2). Also entered were the student's age, gender, rural or urban hometown status, a factor 
to indicate if he or she had ever visited the United States, and another to indicate if the student was a transfer student. Finally, the students' pretest and post test scores were entered.

Data from Part 1 and Part 2 of the inventory were analyzed by using analyses of variance (ANOVA's ) because an ANOVA tests the difference between two or more means. An ANOVA was used to determine whether there was a significant difference between the control group and the treatment group in regard to the dependent variable of age. Two more ANOVA procedures tested whether the independent variables of gender and hometown (rural or urban) had a significant effect on the dependent variable which was termed "difference score"; this refers to the difference in the scores between the first and second administration of the SPACCI.

The data from the first administration of the SPACCI was also compared to determine if there were a difference between the control group and the treatment group in each group's prescores. This was tested by an ANOVA comparing prescores. Finally, a one-way analysis of variance was computed to determine if the dependent variable "difference score" was affected significantly by the independent variable "group" (lecture group versus manga group)

While the data from Parts 1 and 2 of the inventory were analyzed using statistical methods, the researcher did a content analysis of the responses in Part 3. This was accomplished by looking for common themes and repeated phrases in the responses. A tally was made of these phrases and themes, so that dominant ones could be identified. 


\section{Chapter 4: Results}

Introduction

This chapter presents the results of the data analysis. Data from Parts 1 and 2 of the SPACCI were analyzed by using ANOVA to answer several questions:

1990 Is there a significant difference between the mean "difference score" (that is,the post-score minus the prescore) of female students and the mean "difference score" of male students?

1991 Is there a significant difference between the mean "difference score" of urban

students and the mean "difference score" of rural students?

1992 Is there a significant difference between the mean age of the lecture group and

the mean age of the manga group?

1993 Is there a significant difference between the mean prescores on SPACCI of

the lecture group and the mean prescore on SPACCI of the manga group?

1990 5. Finally, is there a significant difference between the mean "difference score"

1991 of the lecture group and the mean "difference score" of the manga group?

In addition to those questions, Part 3 of the inventory was analyzed by a content analysis in order to elaborate on student responses to Part 2 and review answers to the open-ended question about the students' own perceptions of ways to improve personal property safety.

Gender

$$
\text { Analysis of Parts } 1 \text { and } 2
$$

One of the research questions asked whether male Japanese students and female Japanese students would react differently to the instruction presented on safety. Therefore, it was necessary to determine the gender of the subjects. Of the students tested, 12 were females, although only 11 answered all the items on the inventory. Table 2 shows the data for gender.

Table 2

Table of Group Responses by Gender

Female Male

Control (lecture) $\quad 6 \quad 13$

Treatment (manga) $\quad 5 \quad 15$

$\begin{array}{lll}\text { Total } & 11 & 28\end{array}$

The rationale for gathering this data was to determine the influence of gender on intended behavior. Lenski (1992), for example, found a significant difference in the 
intended precautionary behavior of American female college students, compared to American male college students. It was for this reason that there was an attempt to proportion the genders equally between the control and treatment groups. In addition, after the data were collected, an ANOVA based on the independent variable, gender, was done. The results showed that there was no significant difference in the responses of the students based on their gender $(n=39, p>.05)$. Table 3 summarizes this data for gender.

Table 3

Analysis of Variance for Gender Differences

\begin{tabular}{|c|c|c|c|}
\hline $\begin{array}{l}\text { Source df } \\
\text { gender } 1 \\
\text { group } 37\end{array}$ & & $\begin{array}{l}F \\
0.00\end{array}$ & $\begin{array}{l}\mathrm{p} \\
0.9991\end{array}$ \\
\hline Gender & $\mathrm{N}$ & & Difference in scores: mean \\
\hline 1 (females) & 11 & & 15.818 \\
\hline 2 (males) & 28 & & 15.821 \\
\hline
\end{tabular}

\section{Hometowns}

The students came from all parts of Japan, from Okinawa in the south to Hokkaido in the north. Another research question was whether students from cities would answer the inventory differently from students who live in rural areas. A large number of students came from the metropolitan areas of Tokyo and Yokohama. Twentyone of the thirty-nine students identified their hometown as urban. The rest said they came from a rural hometown. Table 4 summarizes the data for hometown.

Table 4

Table of Group by Rural or Urban Hometown

\begin{tabular}{ccl}
\hline Control & Rural & Urban \\
Treatment & 8 & 11 \\
Total & 10 & 10 \\
& 18 & 21 \\
\hline
\end{tabular}

There was the possibility that students from an urban hometown might have different perceptions about safety issues compared to students from a rural background. Researchers in crime often look at the "ecology" of crime, or the physical characteristics of places that encourage or discourage crime (Sloan, 1992). Weishert and Wells (1996) suggest that rural and urban Americans have different attitudes about the likelihood of crime in their neighborhoods. However, in this research a similar pattern of attitudes 
was not found. Based on the students' self-reports of hometowns, the data show that the independent variable rural-urban does not have a significant effect on the dependent variable, difference of scores, $F(1,37)=3.22$, $p>.05$. Table 5 shows this data.

Table 5

ANOVA for Differences of Hometowns (Rural/Urban)

\begin{tabular}{|c|c|c|c|}
\hline Source & df & $\mathrm{F}$ & $\mathrm{p}$ \\
\hline hometown & 1 & 3.22 & .0807 \\
\hline group & 37 & & \\
\hline
\end{tabular}

Hometown $\quad \mathrm{N} \quad$ Difference in scores, mean SD

1 (rural) $\quad 18 \quad 18.167 \quad 6.012$

2 (urban) $\quad 21 \quad 13.809 \quad 8.652$

Age

Another variable considered was the age of the students. However, the students tended to come form the same age cohort. The mean age of the control group was 18.84 years. The mean of the treatment group was 19.05. This closeness of age is not surprising, as students in Japan tend to participate in significant events (such as beginning college) in step with their "cohorts", or members of their same age group. An analysis of variance was done on these differences; it showed that the difference in age was not significant. $F(1,37)=.30, p>.05$. Table 6 summarizes the data for age.

Table 6

Analysis of Variance for Age

\begin{tabular}{llll}
\hline Source & df & $\mathrm{F}$ & $\mathrm{p}$ \\
group & 1 & .30 & .5855 \\
students & 37 & & \\
Group & $\mathrm{N}$ & Mean & $\mathrm{SD}$ \\
\hline 1(control) & \multicolumn{1}{c}{19} & 18.842 & 1.068 \\
2(treatment) & 20 & 19.050 & 1.276 \\
\hline
\end{tabular}

\section{Pretest Scores}

The pretests of the two groups were compared. If the control group had scored significantly lower on the pretest, it would have confounded the data found on the post test. The pretest mean of the control group was 74.63 points. The prescore for the 
treatment group was 75.65 points. The standard deviations for the control and treatment groups were 5.52 and 6.67, respectively. An ANOVA indicated that the small difference between the two groups was not significant at .05. (See Table 7)

Table 7

Analysis of Variance for Prescores

\begin{tabular}{llll}
\hline Source & $\mathrm{df}$ & $\mathrm{F}$ & $\mathrm{p}$ \\
group & 1 & 0.11 & 0.74 \\
students & 37 & & \\
Group & $\mathrm{N}$ & Mean & $\mathrm{SD}$ \\
\hline 1(control) & 19 & 74.632 & 5.520 \\
2(treatment) & 20 & 75.650 & 6.675 \\
& & & \\
\hline
\end{tabular}

\section{Previous Experiences of the Students}

Finally, another factor to consider was the experience of the students with college life and with life in the United States. Of the 39 students who responded to the inventory completely, only four had transferred from another college and only three had ever visited the United States. The distribution of these factors was too narrow to consider them as separate variables.

Groups and Testing Occasions

The study contrasted a traditional lecture approach to learning with a manga, a comic book approach. This contrast was for two groups of students. Thus, group was a between-subject independent variable. Each group was tested prior to instruction (pretest) and after instruction (post-test). Thus, testing occasion was a within-subjects independent variable. The dependent variable was the student's score on the Safety Practices on American Campuses Inventory (SPACCI). Accordingly, the primary design crossed two groups (lecture versus manga) with two testing occasions (pretest versus post test) to determine the effects of these two independent variables on the SPACCI score.

To test the hypothesis that the illustrated comic book intervention would be more effective than the traditional lecture intervention, a one-way analysis of variance was computed. In this analysis, a difference score (post-test minus pretest) was used as a dependent variable. The independent variable was group (lecture versus comic book). This analysis of variance yielded a significant effect, $F(1,37)=4.31, \mathrm{p}<.05$. This finding indicates that the comic book approach produced a significantly higher gain in SPACCI score than did the lecture approach. The mean difference score between post and pre was $\mathrm{M}=18.4(\mathrm{SD}=5.9)$ for the comic book group and was $\mathrm{M}=13.8(\mathrm{SD}=7.6)$ for the lecture group. These differences are shown in Table 8 and also depicted in Figure 1. 
Table 8

One-way Analysis of Variance for Difference Score

\begin{tabular}{llll}
\hline Source & df & F & p \\
group & 1 & 4.31 & $<.05^{*}$ \\
students & 37 & & \\
Group & $\mathrm{N}$ & Mean & Standard Deviation \\
control & 19 & 13.8 & 7.6 \\
treatment & 20 & 18.4 & 5.9
\end{tabular}

Note. $* \mathrm{p}<.05, * * \mathrm{p}<.01$

Figure 1.

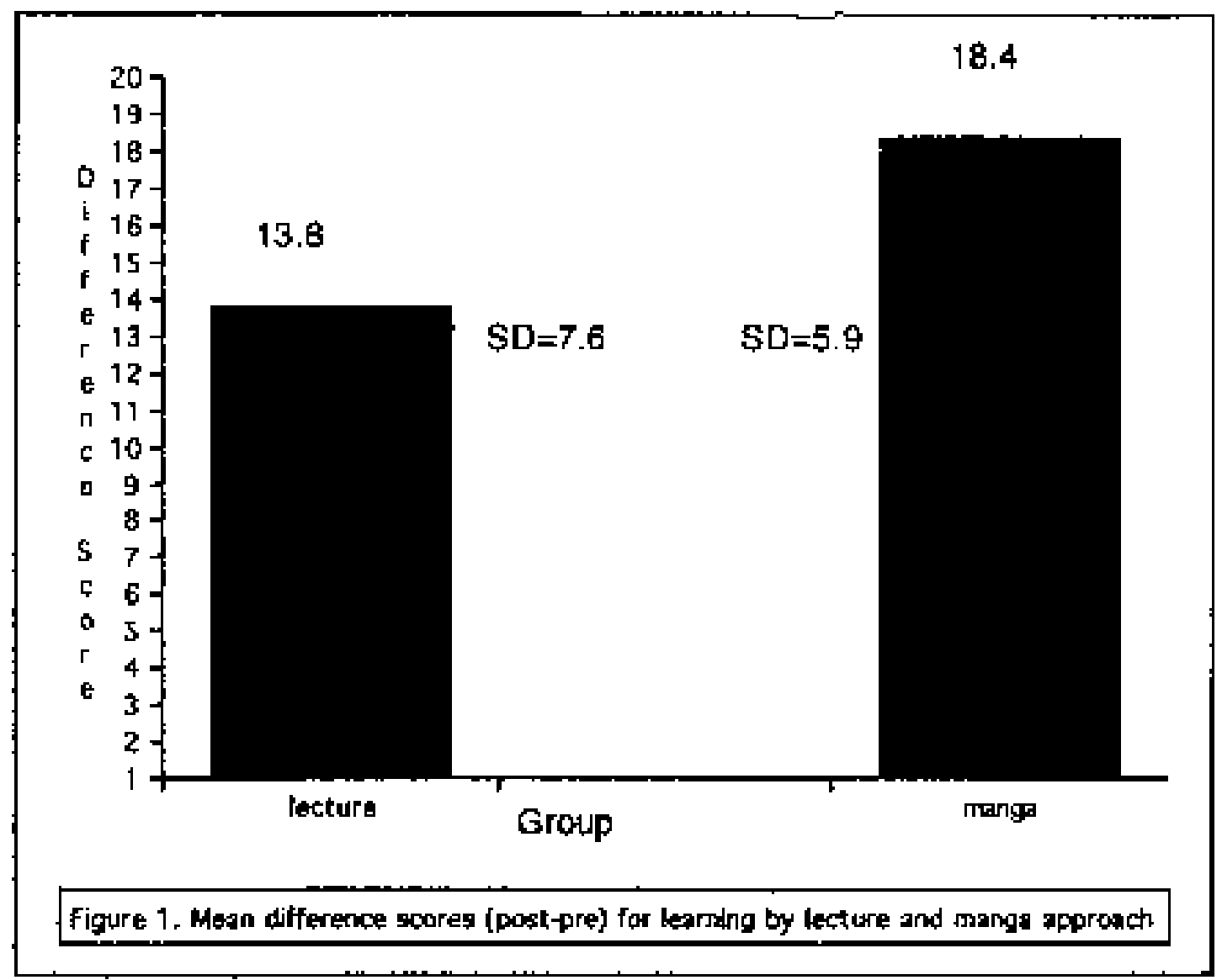

To examine the data for potential interaction between group (lecture versus comic book) and testing occasion (pretest versus post-test), a two-way analysis of variance was calculated. For this analysis, group was an independent variable (between subjects). 
This was crossed with testing occasion (pretest versus post-test) as the other independent variable (within subjects). The dependent variable was the score on the SPACCI. The group main effect did not produce a significant finding, $\mathrm{F}(1,37)=2.55, \mathrm{p}>.05$.

The mean scores and standard deviations for the lecture and comic book groups respectively were $\mathrm{M}=81.8, \mathrm{SD}=10.1$ and $\mathrm{M}=84.7, \mathrm{SD}=10.9$. The testing occasion main effect yielded a significant finding, $\mathrm{F}(1,37)=221.4$, $\mathrm{p}<.01$. The mean scores and standard deviation for pretest and post-test respectively were $\mathrm{M}=75.2, \mathrm{SD}=6.0$ and $\mathrm{M}=91.4, \mathrm{SD}=7.5$. The more important effect and the focus of this analysis was the interaction of these two independent variables. The interaction of group by testing occasion was significant, $\mathrm{F}(1,37)=4.31, \mathrm{p}<.05$. The means and standard deviation for this interaction as well as a graph of this interaction are presented in Figure 2.

\section{Figure 2.}

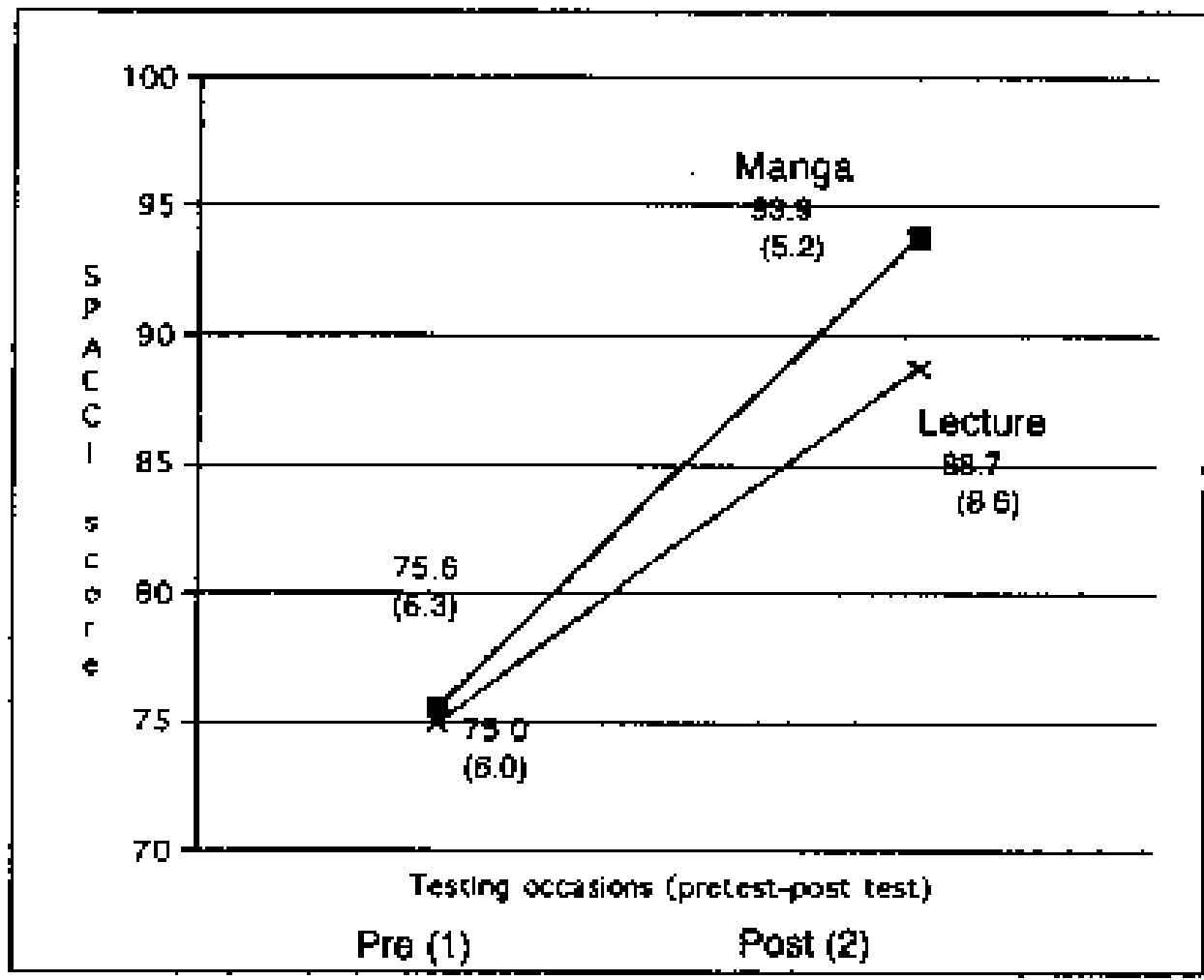

Means and standard deviations for the interaction of group (lecture versus manga) by testing occasion (pre versus post) on SPACCI

An interaction and follow-up analysis was done by the Duncan Multiple Range Test on the pretest means of the lecture group (75.0), and the manga group (75.6) and the post test means of both groups (88.7 and 93.9, respectively). These indicate that (a) there is no significant difference between the two groups on the pretest, (b) both groups learned 
significantly from the pretest to the post-test, and (c) the manga group learned significantly more than the lecture group.

Approximately three months after the initial instruction on safety, the students were given the same inventory as a post post test. Seventeen students from the control group and seventeen students from the treatment group completed the answers on this occasion. The students overall scored lower on the post post test than on the post test, although the means were higher than the pretest. The results showed no difference between the two groups, $F(1,33)=.02$, which was not significant at p>.05 (See Table 9). The scores and means are shown in Appendix F.

Table 9

ANOVA on Post Post Test

\begin{tabular}{llll}
\hline Source & $\mathrm{df}$ & $\mathrm{F}$ & $\mathrm{p}$ \\
group & 1 & .02 & .89 \\
students & 33 & & \\
& & & \\
Group & $\mathrm{N}$ & Mean & Standard Deviation \\
control & 17 & 86.2 & 9.96 \\
treatment & 17 & 86.3 & 10.92 \\
\hline
\end{tabular}

Analysis of Part 3: Content Analysis of SPACCI

This part of the inventory elicited responses to elaborate some of the previous questions. It was also included in the SPACCI in order to address whether Japanese freshmen would report intentions to engage in more prudent behavior. The overall impression from these answers is to reinforce the conclusion that the intended behavior of Japanese students regarding safety is subject to change from instruction, at least in the short term.

Part 3 of the inventory began by asking for the name and room number of the students' Resident Assistant. The treatment group did better on these questions on the post test: 11 students knew the answers in the comic book group (55\%, $\mathrm{n}=20)$, compared to six in the lecture group $(32 \%, \mathrm{n}=19)$. In the post post test, the comic book group did even better: $85 \%$ knew the correct answers, compared to $76 \%$ of the students in the lecture group.

Questions \#3 and \#4 of Part 3 asked the students how much money they would feel comfortable keeping in their wallet or in their room. The word "comfortable" presented some difficulty in translation. The Japanese translator explained that the students might misconstrue the question to mean "How much money would make you comfortable or feel happy?" Other students on the panel of translators agreed that they would be likely to think of that question as a hypothetical question about their desires or daydreams. They decided that the closest translation would be to ask the students how much money they would feel "normal" about carrying or keeping in their room. There was a wide variance in the answers to these questions. Regarding money in their wallets, 
the range was from $\$ 0$ to $\$ 500$ in the pretest and from $\$ 0$ to $\$ 300$ in the post test. In the post post test, the answers varied between $\$ 0$ and $\$ 5000$. In answering the question about keeping money in their rooms, the range was from $\$ 0$ to $\$ 1000$ on the pretest, $\$ 0$ to $\$ 600$ on the post test, and $\$ 0$ to $\$ 5000$ on the post post test. The average amount that the students in the control group said they would feel comfortable about carrying on them was $\$ 116$ on the pretest, $\$ 79$ on the post test, a decrease of about $32 \%$. However, on the post post test, this figure increased to an average of $\$ 351$. One student in this group changed his answers from $\$ 500$ (pre test) to $\$ 200$ (post test) to $\$ 5000$ (post post test). Because of the objective nature of the testing it is not known why he changed his estimates so drastically. However, he seems to be an anomaly. If his answers are not computed with the others, the control group's average answer in the post post test is $\$ 60$. In contrast, the students in the treatment group reported averages of $\$ 106$ on the pre test, $\$ 90$ on the post test, and $\$ 55$ on the post post test. With the exception of the one student in the control group, it appears that all the students revised their opinions about their intention to carry money in the direction of a safer reply.

In response to the question about keeping money in their rooms, students in the control group said they would feel comfortable with $\$ 198$ in their room on the pretest but only $\$ 130$ on the post test, a decrease of about $34 \%$. On the post post test, it increased to $\$ 356$, again because of the one outstanding answer of $\$ 5000$. Without this one response, the average is $\$ 65$. In the treatment group, the figures are $\$ 156$ (pre test), $\$ 108$ (post test) and $\$ 91$ (post post test). It is impossible to compare the difference between the two groups because they had such a wide variance within each group in their responses. However, these responses do reinforce the impression from the answers to the questions on Part 2 that most of the students in both groups intend not to carry large sums of money or to keep large sums of money in their residence hall rooms.

The fifth and sixth questions on Part 3 asked the students to recall numerical information (the telephone numbers for campus Security and 911). Peeck (1974) contends that visual presentations such as the comic book facilitate retention of information. The test results bear out that observation for the short term but not for the long term. On the post test, $81 \%$ of the students in the manga group were able to recall the information, compared to $74 \%$ of the students in the lecture group. However, on the post post test, only six students in each group could recall the numbers. Therefore, it may be concluded that the manga group had an advantage in the short term, but failed to retain this advantage over time.

The seventh question asked students if they could lock their dormitory room doors by pushing in the button. The majority of students in both groups correctly indicated that they knew this was the wrong way to secure the door in the post and post post tests.

On the question (\#8) regarding the ability to write checks, the majority of students in both groups answered that they knew how to write checks. Regarding credit cards (question \#9) all but two students (one in each group) have a credit card. These answers may reflect the fact that these lessons are taught in the ESL classes during the students' first months on campus.

The final question was open-ended, to elicit comments and suggestions from the students about safety. The question asked, "What can this university do to make you feel safe here?" Only 23 out of 39 students responded to this question. In both groups, the most common response was to suggest increasing the number of Security personnel and 
increasing the amount of patrolling done by Security. The responses were as follows (the totals do not add up to 23 because some students made multiple suggestions):

Increase Security and increase patrols

There is nothing more the university can/should do;

students are responsible for their own safety

4

Teach more about safety (including role playing,tours) 4

Install safes in residence hall rooms 2

Install more lights outdoors 1

Allow only female students in the female dormitory 1

Show the manga to the other group $\quad 1$

On the post post test, 18 students responded. Their responses are listed below:

Increase patrols 4

Increase lighting $\quad 3$

Nothing more can/should be done $\quad 2$

The dormitories are too dangerous $\quad 2$

Install more locks and safes $\quad 2$

Install a gate into the university 1

Install a police box (koban)at the university 1

Have a student crime watch 1

Have an orientation 1

The university should show more selectivity in the students it admits 1

The university should have perfect Security 1

The implications of these suggestions will be addressed in the next chapter.

In summary, the results of Part 3 of the post post test are similar to the results on

Part 2 of the post post test. Both of the groups lost some of the learning that they had

acquired either from the lecture or comic book. Also, there seemed to be little difference between the answers of the treatment group and the control group. 


\section{Chapter 5: Discussion and Conclusions}

This chapter will summarize and interpret the results of the research. First there is a discussion of the purpose, methodology, and analysis of the data. The next section will cover implications for three areas: for the preparation of instructional materials, for instruction, and for student safety. Then recommendations for further research will be discussed.

Purpose of the study

\section{Summary}

The purpose of this study was to investigate a method of instructing incoming Japanese freshmen in areas of personal property safety. The current method of instruction, which depends on oral presentations, appears to be of limited effectiveness because of the limited language skills of the new students. A method that drew upon a visual presentation and the acceptance of comic books in their culture was recommended as a more effective way to instruct students about precautionary behavior. The purpose of this research was to learn how to develop such a method of instruction and to test its effectiveness on an actual group of incoming Japanese freshman students. Methods

A group of 40 students at Salem-Teikyo University who arrived from Japan in April 1998 was used for the instruction in personal property safety. It was planned that the students would be stratified by gender, rural or urban hometown, and the question of whether they had transferred from another college or had traveled in the United States before. However, the latter two factors (transfer and travel) were not used as the number of students in those categories was too small. The students were randomly assigned to one of two groups. The first group received instruction by the traditional means: a lecture on safety followed by a translation into Japanese. The second group heard the same message while viewing a comic book that illustrated the lesson.

The goals of the instruction were developed with input from a panel of American and Japanese experts. The comic book was developed, based on research for preparing educational materials and with the advice of a focus group of Japanese students. Data were collected using an inventory instrument (SPACCI) that was created specifically for this research. In the preparation and testing of the instrument and the comic book, a panel of American experts and the focus group of Japanese students were frequently consulted. A pilot study was conducted on upperclassmen students. Difficulties in translating English into Japanese were discovered and addressed before the inventory was given to the freshmen. The pilot study established the reliability of the inventory instrument. The panel of American experts was polled to establish the content validity of the instrument. Once the reliability and content validity were established, the freshmen students were given the inventory as a pretest before their instruction and as a post test after their instruction. Of the 40 students who took the pretests and post tests, 39 completed both tests and the data from their inventories were analyzed. Three months later, a post post test was administered to both groups. At that time, 34 students participated in the testing.

Data Analysis

Variables were tested by using analyses of variance to discover possible effects of age, gender, hometown distinctions, and prescores. These variables were 
found to be not significant. The answers to the inventory were coded from 1 to 4 and the scores were analyzed. The main effect, that is whether the students in both groups changed their answer significantly from the pretest to the post test, was analyzed and found to be significant at the .01 level of probability. Then the post scores of the two groups were compared to see if the treatment (comic book) group scored significantly differently from the control group. Their answers were found to be significantly different at the .05 level of probability. Therefore it was concluded that the comic book was, for the short term, a more effective mode of instruction than the lecture for teaching about safety issues.

The post post test indicated a loss of the main effect. The scores for the students in both groups were lower in the post post test than they were in the post test. The hypothesis that students receiving instruction from a comic book would retain the instruction better than students who heard a lecture was not borne out by the research. Both groups scored higher than they had in the pretest, but the treatment group did not score significantly higher than the control group.

\section{Conclusions}

To be effective, a mode of instruction should take into consideration the student population for which it is intended. (Burbank and Pett, 1986 and 1988; Fons, 1994; Gillmore, 1992; Hutton, 1990; Thiagarajan, 1976). Japanese students who come to the United States for a university education present certain particular challenges. First, they come with fewer expectations about the dangers on American campuses and with less experience in the means for protecting their valuables from these dangers. There are two main reasons for this. The first is the result of their cultural orientation in which personal property is protected by a societal sanction against theft. Because the society puts so much emphasis on cooperation and harmony, most Japanese nationals are reluctant to do anything that would endanger their acceptance by their peer groups (Fenwick, 1983). Therefore there is less crime in Japan. The second reason is the Risk Perception Theory, which explains that certain populations are less likely to take seriously their vulnerability to negative life experiences. Because adolescents often operate under the "it can't happen to me" mind set, they are particularly vulnerable and less likely to engage in precautionary behavior, whether this means engaging in safe sex, taking medical treatment, or locking their doors (Perloff and Fetzer, 1986; Weinstein, 1984). Thus Japanese freshmen are under a double threat: their culture protects them from feeling vulnerable about their property and their age predisposes them to take risks.

Another aspect of this student population that should be taken into account is their lack of facility in English. For many reasons, Japanese students usually do not come to the United States with a facility for communicating verbally in English. Written English may also be problematic because Japanese students may be more visually oriented to learning information. The reason for this is that they use kanji, a system of writing that has Chinese origins. Kanji uses strokes to make pictures to represent words rather than letters to form words.

The final aspect of cultural differences that have an impact on the students is that information in Japan is often presented in manga or comic book format. This is an old and acceptable part of their culture, lacking the connotation of frivolity that many Americans associate with that particular written form.

In summary, Japanese students typify a population that may have difficulty with 
oral and written English, that may prefer visual learning, and that readily accept comic books as a source of educational information. For all these reasons, it seems reasonable to assume that a comic book might be an effective way to present information to new Japanese students. This assumption was borne out by this research. The two groups received exactly the same instruction. The only thing that varied was the method of presenting the material- comic book form or lecture. The lecture group did better on the post test than the pretest, but did significantly poorer than the comic book group in the post test. Therefore the conclusion was made that the comic book was an effective way to teach these students, at least in the short term.

The caveat about the effectiveness of a comic book as a short term learning tool is necessary because the post post test results showed that both groups failed to retain the learning that they had achieved. The treatment group did no better or worse than the control group. Some reasons for these results should be discussed. The first consideration is the fact that the intervention occurred on only one occasion. However, the students had been acculturated to taking safety for granted by years of experience. It may be that the cultural influence of their experience was stronger than the one intervention of instruction.

In addition, the students had been separated during the initial instruction and testing, but they were together in a large room for the post post test; it was not possible to insure that no collusion on answers occurred. Thus the students who received instruction from the comic book may have shared answers with the control group.

Another consideration is the time frame. During the three months between the post test and the post post test, there was no formal instruction to reinforce the learning that had taken place during the Orientation period. No mention of safety issues or the manga was made. Without reinforcement, it might be expected that there would be some lack of retention. Also, in the three months between testing occasions, the American students had left for summer vacation. The university population during the summer months was almost entirely Japanese. Therefore there may not have been the same sense of vulnerability as would have been the case if other students had been present on campus. Then too, after three months on an American campus, the students may have simply had a more relaxed attitude about safety issues. This would be especially true if they had had some prior misgivings about the safety of the United States and discovered that their environment was very different from those preconceptions. Additionally, the post post test took place at a time when some of the students may have felt less cooperative about completing the inventory. By July, some of the students may have felt culture shock because the initial euphoria about living in a foreign country had left. This is borne out by the drop in the number of students who participated. All these variables were beyond the control of this research and may account for some of the diminished results on the post post test.

Implications of the Study

Implications for the Preparation of Educational Material

One focus of this research was to describe the process of preparing a comic book as an educational tool. Anderson and Tomkins (1983) remark that the classroom teacher has an advantage in preparing educational materials because of the teacher's familiarity with the students and their needs. Despite this advantage, many teachers are uneasy about preparing their own materials. One reason may be a sense of inadequacy in 
illustrating the material. The lack of artistic talent is not an impediment. In this research, a professional cartoonist was employed. He draws for a local newspaper and often illustrates brochures for the local Arts Center. Contacting local groups to see whom they employ for their publications is one way to find artists. Another source is high school art teachers and art students. For the educator who has some artistic talent, there are books available to teach the methods of cartooning (see, for example, Mort Gerberg's Cartooning: The Art and the Business). In addition, there are computer programs that are useful for educators with limited art skills. Many can be found by searching for “ cartoons and clip art" on the internet. For example, The Learning Company produces "Art Lesson" (at http:// www. cdrom.com/home.html) and Task Force clip art is available at http: //www.nvtech.com/index.html. Finally, an important source of artwork may be Japanese students themselves. Many Japanese students draw cartoons for their own enjoyment because cartoon characters are such a popular form of entertainment in Japan. A lack of artistic talent should not discourage the educator who wants to produce original materials because there are many sources of help available.

Another concern in the production of educational materials is the textual content of the materials. This research would suggest that using students and other educators as an expert panel is an efficient way to get feedback on the objectives and content of the materials.

Finally, the mechanics of producing educational materials should not discourage the would-be author. It is not necessary to have expensive publishing equipment. The comic book used in this research was produced with the use of a computer as a wordprocessor and a photocopy machine, two tools that are readily available at most educational institutions.

Implications for Instruction

In the United States, comic books have had a mixed reputation. One of their earliest uses was to enculturate immigrants who came in the first part of this century. Comic books were considered an ideal way to teach about American manners and customs. More recently, federal agencies as diverse as the U.S. Forest Service and the Food and Drug Administration have used comic books for educational purposes. Nevertheless, for some people, comic books have a connotation of childishness about them that prohibits their use as serious teaching aids in educational settings. The research would suggest that this vehicle could be considered as a mode of instruction.

This conclusion has implications for institutions of higher learning. As Japanese students continue to come to American colleges and universities, educators will try to orient the new students to the culture and practices of American colleges. Part of that orientation process will be attempts to provide safety instruction, so that students will avoid being victimized, especially during the important first weeks of their stay. If colleges present this important information in an oral format, through a lecture, they may miss an opportunity to truly orient the students. How to present this information more effectively, then, becomes a curricular matter. This research would indicate that a visual approach, particularly one that incorporates the comic book format that is comfortable to them from their own experiences, is an effective way to convey information to Japanese students during the orientation period.

Japanese students are not the only ones who may benefit from a comic book format, however. Chinese, Taiwanese, and Korean students also share the use of 
pictographs, a language form that is more pictorial than the English alphabet. Since they share this form of writing, they may benefit from a more visual presentation of information too.

Also, the topic of personal property safety is not the only one that could be addressed by a comic book. For instance, students need to know how to protect themselves from personal harm. They need to know what behaviors to engage in (such as walking in well-lit streets) or to avoid (such as not hitchhiking) in order to protect themselves. A comic book may be a good vehicle for addressing these issues.

In addition, international students want to know how to fit into American society. Dating and personal relationships are often baffling areas for students who come from diverse backgrounds. In trying to fit in to their new social environment, there is a danger that they may be vulnerable to drug and alcohol abuse and date rapes. A comic book on social norms could be helpful in this area.

Finally, academic courses may also want to consider ways to use more visual material in their classes. It would seem logical that illustrations would be especially valuable in English as a Second Language (E.S.L.) textbooks. Often an ESL text will use the occasional cartoon to illustrate an application of a grammar point, for instance. However, it might be beneficial to use cartoons and illustrations more lavishly, to illustrate passages of a reading selection for example. Comic books, in their entirety, could be used as reading material.

However, the application of illustrations is broader than remedial or developmental classes such as E.S.L.. For example, Diane Lynch (1997) used comics in her middle school mathematics class to encourage communication in mathematics. Comics could be used to demonstrate lessons on computers or laboratory safety. Nearly every academic discipline taken by Japanese students could use comic books effectively in its classes.

Implications for Safety on Campuses

While it was not the main focus of this research, the issue of student perceptions about their safety became a valuable outcome of the open ended question on Part 3 of the SPACCI. The question asked the students what they thought the university could do to improve their security on campus. The most common answer was to increase the amount of Security personnel and to have more patrols around the campus. This may reflect the ubiquitousness of the kobans or police boxes in Japan. As one writer explained "Kobans mean never having to wonder where the cops are; they are in their little booths, watching" (Sanger, 1995). The students indicated that they would feel safer if Security were more visible and were as close at hand as it is in Japan. This recommendation is supported by research done by John J. Sloan, in his 1992 study of 400 American colleges and universities. He concludes "... given that property crime constituted the vast bulk of campus crime, there is reason to believe that something can be done about campus crime (38)". He recommends increasing the ratio of security personnel to students and cites the example of the campus security officials at the University of Alabama-Birmingham where the campus police are increasing the use of foot, bike, and mounted patrol on campus (39).

Another response from the students was a suggestion to increase the education of the students about safety issues. Two students suggested role playing as the methodology that they thought would be most suitable to teach safety issues. Another student 
mentioned having a tour of the campus for freshmen. Finally, one student who was in the treatment group suggested that the other students (in the control group) should also be given the comic book on safety.

Other suggestions for safety included several who said they would like to have safes in their rooms or locks on closets and desk drawers. Others requested better outdoor lighting on campus. Some responses suggest that the students were looking for models of safety from their home culture. For example, one student proposed having a gate at the entrance to the university. While this would be an unusual feature at an American institution, it is common in Japan for gates to secure a campus; cars are not permitted to enter the campus after classes are over. Usually the koban is situated close to the gate, which may account for one student's suggestion to have a koban on the campus. Another student recommended that only female students be allowed in the female dormitory. Coeducational dormitories are not the norm in Japan. Finally, there was a suggestion to have a student crime watch; in Japan, every apartment building has its own citizen crime watch. It appears that the students were reminded of safety precautions that are a part of the Japanese culture when they made suggestions about improving safety at their American university.

In contrast to those suggestions, some students did not believe that the university should do more. Two answered that safety was the responsibility of each individual, not the university. One said that the university already did enough, and another said it was impossible for the university to do more. However, these four students were in the minority compared to those who did feel that there were steps the university could take to make them feel more secure.

\section{Recommendations for Further Research}

This study focuses on the needs of Japanese students who were newly arrived at an American university. Additional research needs to be done to ascertain how long the effects of instruction last and what circumstances could maintain or improve retention. Peeck' s research (1974) suggests that illustrations enhance retention of learning. However, his post post research was done after a week. O'Keefe and Solman (1987) found that illustrations had a facilitative effect, possibly because they serve as mnemonic strategies. However, it has not been determined how lasting this effect is. This effect was not seen in the post post test of this research, in which the group receiving illustrations performed in a similar manner to the group that was instructed orally. There were limitations to this research in the post post test, as noted before; the major factor was that the two groups were not separated during the post post test, as they had been during the other tests. This was due to the fact that the first tests took place during Orientation, when it was practical to separate the groups. However, the post post test was administered when the students had begun their regular classes. It was not possible to break them into their original groups. They were tested in a large auditorium, which made it difficult to control the discussions and prevent collusion on the answers to the test. In further research, the post post test could be administered in a way to ensure that the groups did not meet and discuss their opinions. It might be beneficial to administer the tests to two groups of students from different campuses. Since the issue of retention is an important issue and it was not clarified in this research, it would be worthwhile to investigate the level of retention at different time periods in subsequent research.

Another question arises from the format of the inventory. The students had the 
option of choosing from four answers. In order to limit ambiguity, there was no response that said "I don't know". The students could choose a strong yes, a yes, a no, or a strong no. A seven point Likert scale would reveal more detailed information about the students' reactions to the instruction and the extent of their retention of the material. It might also be helpful to include more factual questions in the inventory to see if there is a difference between retention of that kind of information and retention of behavioral intentions.

Another area for further research is the area of the affective impact of the comic book instruction. The quantitative techniques of collecting data that were used in this study could profitably be supplemented by qualitative techniques of data collection. It would be worthwhile to interview students about their preferences in instructional techniques. This research did not investigate the students' emotional response to the manga, however some students in the manga group volunteered comments on their survey. While one student wrote that the manga was just "so-so", another said it was good, and two wrote that it helped them to understand the material better. One student said that the emotions needed to be depicted more clearly, but another seemed to empathize with the character when she wrote "Koji did not seem to have a good experience in the United States." Finally, another student deemed the manga "cool". Further research could clarify the students' varying reactions to a manga as an instructional tool.

In addition, this research did not investigate whether the students' actual behavior changed as a result of the instruction. Interviews with students and anecdotal information would complement the numerical data and reveal information about students' true behavior, as well as give insights into the reasons for that behavior.

In terms of the comic book, other questions remain. The "good guy-bad guy" is one format to teach safe behavior. It may be that a different style of writing would be more effective. For example, what impact on students would there be if the comic book had been written by students in the form of autobiographical stories about their real experiences? Another method could capitalize on the Japanese system of senpai-kohai (senior and junior students) by making the protagonist of the story a senpai who is giving advice to his kohai. Still another possibility would be to use a super hero figure as the protagonist, in the style of Japanese animation movies. Research could be done to indicate whether students prefer realistic story lines or more mythical ones.

Another concern is the illustrations themselves. Research needs to be done to determine if Japanese students respond more readily to cartoons drawn by Japanese artists. Perhaps there are techniques in drawing that American artists could copy in order to increase the appeal and comprehensibility of their artwork. Another area to explore is whether illustrations such a photographs work as well as cartoons with students.

While this research looked at a comic book as an alternative form of instruction, there are other possibilities which were suggested by the students themselves. Role playing has the advantage of being a visual method of instruction. Another possibility is the use of videos.

Further research might address some of the limitations inherent in the small population sample of this study. With a larger sample, it would be possible to gather more information about the effects of gender, age, and hometowns on student safety perceptions. These variables had no significant effect on the outcome in this study but 
the sample size is a real limitation.

Another way to gain a larger perspective would be to test students at different age levels to see what impact the instruction by comic book has. It may be that younger students would be more impressed by the safety instruction and retain the instruction longer.

Another area that is intriguing from this research is in the area of psycholinguistics. Since Japanese uses kanji, a pictorial form of writing, perhaps there is a difference in the way these students process information from the written form. Kikuchi (1996) has done research into the difference between Japanese natives and English speakers in the way they process kanji. He suggests that there is a difference in the way the two groups perceive the written forms in Japanese. It would be useful to know to what extent the same is true of the processing of English letters. It may be that there is a difference in the memory processes involved in storing information from pictures as compared to information presented by English words. This would have implications for the curricular methods we use to teach students who are pictorially oriented. We are only beginning to learn the functions of the brain and how language is learned and stored. All these are questions that would be worthwhile for further investigation.

The purpose of this research was to investigate another method of teaching a group of students with particular needs regarding their safety. The research indicates that the use of a manga, or comic book is effective in transmitting information for at least the short term. Therefore, it supports the use of comic books as another teaching method for educators. 


\section{References}

A gun tragedy again. (1994, March 31) Mainichi Daily News. Quoted in White, M.I. and Barnet, S. (Ed.) Comparing cultures: Readings on contemporary Japan for American writers (p. 393). Boston: St. Martin's Press .

Adler, F. (1983) Nations not obsessed with crime. Littleton, Colorado: Fred B. Rothman \& Co.

Anastasi, A. (1976) . Psychological Testing. NY: Macmillan Publishing Co.

Anderson, R. M. \& Tomkins, G. S. (1983) . Understanding Materials: Their Role in Curriculum Development. Vancouver, Canada:University of British Columbia.

Anderson, R.S. (1975) Education in Japan: A Century of Modern Development. Washington, D.C.: U.S. Department of Health, Education, and Welfare.

Ajzen, I. \& Fishbein, M. (1980). Understanding Attitudes and Predicting Social Behavior. Englewood Cliffs, NJ: Prentice-Hall.

Balan, P. (1989) . Improving instructional print materials through text design. Performance \& Instruction, 28, 13-18.

Ball, H. G. (1976) . Who is Snoopy? Language Arts, 53, 798-802.

Barron, D. (1991) . Zap! Pow! Wham! Comics, graphic novels, and education. School- Library- Media Activities Monthly, 8, 48-50.

Bastion, L.D. \& Taylor, B.M. (1991) . School crime: A national crime victimization survey report. Report for the U.S. Department of Justice. (ERIC Document Reproduction Service No. ED 339 133)

Beauchamp, E.R. (1992) Japanese and US Education Compared. Bloomington, Indiana: Phi Delta Kappa Educational Foundation

Brislin, R. W., Lonner, W. J. , \& Thorndike, R. M. (1973). Cross-cultural research methods. NY: John Wiley \& Sons.

Burbank, L. \& Pett, D. (1986) Designing printed instructional materials. Performance and Instruction Journal, 8, 5-9.

Burbank. L. \& Pett, D. (1988) Designing instructional materials: Some guidelines. Blackburn, VA: International Visual Literacy Association. (ERIC Reproduction Service ED 302 230). 
Chang, D.H. (1988). Crime and delinquency control strategy in Japan: A comparative note. International Journal of Comparative and Applied Criminal Justice, 12. 139-149.

Davis, D.C. (1995) . Crime on campus: A qualitative examination of unreported crime on the college campus. Doctoral dissertation, Boston University.

De la Rue, D. \& Ruback, R. B. (1987). Throwing caution to the wind: Rationales for risky behavior (Paper presented at the Annual Meeting of the Southeastern Psychological Association, 33rd) Atlanta, GA, March 25-28, 1987 . (ERIC Document Reproduction Service No. ED 284 121).

Donald, D. (1983) . The use and value of illustrations as contextual information for readers at different progress and developmental levels. British Journal of Educational Psychology, 53, 175-185.

Dubin, F. \& Olshtain, E. (1986) . Course Design: Developing Programs and Materials for Language Learning. NY: Cambridge University Press.

Embree, J.F. (1939). Suye Mura: A Japanese Village . Chicago, Illinois: University of Chicago Press.

Fenwick, C.R. (1983) The juvenile delinquency problem in Japan: Application of a role relationship model. International Journal of Comparative and Applied Criminal Justice, 7 . 119-128.

Fishbein, M. \& Ajzen, I. (1975) . Belief, Attitude, Intention, and Behavior. Reading, MA: Addison-Wesley Publishing Co. .

Fishman, G. \& Dinitz, S. (1995) . Japan: A country with safe streets. In W. S. Laufer and F. Adler (Ed.), Advances in criminological theory (pp. 111- 126) . New Brunswick: Transaction.

Fons , J. (1994) . Target group characteristics: Are perceptional modality preferences relevant for instructional materials design? Education and Training Technology International, 31, 11-18.

Gerberg, M. (1989). Cartooning: The Art and the Business. Williamsport, PA: William Morrow and Company.

Gillmore, M. R. (1992) The process and pitfalls of developing a culturally relevant curriculum to reduce AIDS among sexually active teenagers: The take 5 project. San Francisco, CA: American Education Research Association. (ERIC Document Reproduction Service ED 351 629). 
Gravetter, F. J. \& Wallnau, L. B. (1992) Statistics for the behavioral sciences: A first course for students of psychology and education. NY: West Publishing Co.

Gudykunst, W. B., Matsumoto, Y., Ting-Toomey, S., Nishida, T., Kim, K., \& Heyman, S. (1996). The influence of cultural individualism-collectivism, self-construals, and individual values on communication styles across cultures. Human Communication Research, 22, 510-543.

Hall, E.T. (1976) Beyond Culture. NY: Anchor Press.

Harasawa, M. (1974) A critical survey of English language teaching in Japan: A personal view. English Language Teaching Journal, 29, 71-79.

Haring, M. and Fry, M. (1979) . Effect of pictures on children's comprehension of the written text. Educational Communication of Technology Journal, 27, 185-190.

Head, A. (1995). Japan and the safe society. Japan Quarterly , 42, 146-154.

Hoopes, A. (1992) . Update Japan. Yarmouth, Maine: Intercultural Press, Inc.

Hutton, B. (1990). A manual for writers of learning materials. Cape Town, South Africa: Buchu Books. (ERIC Reproduction service No. ED 356 405).

Ito, K. (1993) . Research on fear of crime: Perceptions and realities of crime in Japan. Crime \& Delinquency, 39, 385-392.

Kato, H. (1973). Japanese popular culture: Studies in mass communication and cultural change. Westport, Connecticut: Greenwood Press.

Kemp. J. E. and Dayton, D. K. (1985) . Planning and Producing Instructional Media. N.Y.: Harper \& Row.

Kikuchi, T. (1996) . Detection of kanji words in a rapid serial presentation task. Journal of Experimental Psychology: Human Perception and Performance, 22, 332-341.

Kimizuka, S. (1977) . Teaching English to Japanese. Moab, UT: Tail Feather.

Kleinhesselink, R. R. , \& Rosa, E. A. (1991). Cognitive representation of risk perceptions: A comparison of Japan and the United States. Journal of CrossCultural Psychology, 22, 11-28.

Kristof, N.D. (1995, May 14) . Japanese say no to crime: Tough methods, at a price. The New York Times International, pp.1, 8.

Kumagai, F. (1996) Unmasking Japan Today: The Impact of Traditional Values on . Westport, CT: Praeger. 
Lederman, D. (1993, January 20) . Colleges report 7,500 violent crimes on their campuses in first annual statement required under federal law. The Chronicle of Higher Education, pp. A32- 43.

Lederman, D. (1993, January 20) . Experts say disclosure law allows colleges to omit categories that could give clearer picture of crime. The Chronicle of Higher Education, p. A33.

Lenski, T.J. (1992) . Students' perceptions of campus safety and the effect on intended precautionary behavior. Doctoral dissertation, University of Vermont.

Lesko, M. (1994, January 1). The government works for kids, too. [CD-ROM] Lesko's Info-Power II. Full text from Electric Library, Spring, 1998.

Lewis, C. (1984) A view from the Japanese kindergarten and first grade. (ERIC Document Reproduction Service No. ED 304 374).

Litcher, J. H. \& Johnson, D.W. (1969) . Change in attitudes towards Negroes of white elementary school students after use of multiethnic readers. Journal of Educational Psychology, 60, 148-152.

Lucas, J. (1984). Communication apprehension in the ESL classroom: Getting students to talk. Foreign Language Annals, 17, 593-598.

Lynch, D. (1997). Creativity: A key to understanding. the Mathematics Teaching in the Middle School, 2, 350-351.

Maslow, A. H. (1970). Motivation and Personality. New York: Harper \& Row.

Markus, H. R. \& Kitayama, S. (1991) . Culture and the self: Implications for cognition, emotion, and motivation. Psychological Review, 98, 224-253.

Morton, W.S. (1984) Japan: Its History and Culture. New York: McGraw-Hill, Inc.

OERI. Japanese Education Today: A Report from the United States Study of Education in Japan (1987) prepared by a special task force of the O.E.R.I. and Japan Study Team, (OR 87-500), Washington, D.C.: U.S. Government Printing Office.

O’ Keefe, E. \& Solman, R. (1987) . The influence of illustrations on children's comprehension of written stories. Journal of Reading Behavior, 19, 353-357.

Peeck, J. (1974) . Retention of pictorial and verbal content of a text with illustrations. Journal of Educational Psychology, 68, 880-888. 
Perloff, L. \& Fetzer, B. (1986). Self-other judgments and perceived vulnerability to victimization. Journal of Personality and Social Psychology, 50, 502-510.

Pollack, A. (1995, November 23). In a land lush with cash, the robbers cash in. The New York Times International, p. 4.

Reid, K. (1993). A rhetorical approach to non-discursive messages in information campaigns (Selected readings IR 017 742). Delphi, Greece: Symposium of the International Visual Literacy Association. (ERIC Document Reproduction Services No. ED 393 428).

Reingold, E.M. (1992). Chrysanthemums and thorns: The untold story of modern Japan. New York: St. Martin's Press.

Reiser, R. A. \& Dick, W. (1996) . Instructional Planning: A Guide for Teachers. Boston: Allyn and Bacon.

Roark, M. L. \& Roark, E.W., Jr. (1987). Administrative responses to campus violence. Paper presented at the annual meeting of the American College Personnel Association/ National Association of Student Personnel Administrators, Chicago, Illinois. (ERIC Document Reproduction Service No. ED 286 082).

Samovar L.A. and Porter, R.E. (1991) Communication Between Cultures. Belmont, California: Wadsworth Publishing Company.

Samuels, S. (1970) . Effects of pictures on learning to read, comprehension, and attitudes. Review of Educational Research, 40, 397-407.

Sanger. D.E. (1995) . Tokyo's tips for New York. In White, M.I. \& Barnet, S. (Ed.) Comparing cultures: Readings on contemporary Japan for American writers (pp. 354-357). Boston: St. Martin's Press.

Sawicki, L.F. (1989). Creating an educational comic book. Etc., a Review of General Semantics, 46, 248-249.

Schodt, F. L. (1998). Land of the Running Serial. Civilization, 6, 69.

Schreiber, M. (1995) A nation without guns. In White, M.I. \& Barnet, S. (Ed.) Comparing cultures: Readings on contemporary Japan for American writers (pp. 386-392). Boston: St. Martin's Press.

Sinatra, R. \& Stahl-Gemake, J. (1983) . Using the Right Brain in the Language Arts. Springfield, IL: Charles C. Thomas

Slavin R. E. (1994). Educational Psychology: Theory and Practice (2nd Ed) . Boston: Allyn and Bacon 
Sloan, J.J. (1992). Campus crime and campus communities: An analysis of crimes known to campus police and security. Journal of Security Administration, 15, pp. 31-47.

Tanikawa, M. (1996, August 4). Difficult lesson. New York Times , p.33.

Tanno, D. , Hamazaki, T., Mogi-Hein, Y., \& Takahashi, T. (1995). Japanese students in the U.S. higher education: Their preference for staying in the U.S.A. and academic motivation. College Student Journal, 29, 347-355.

Thiagarajan, S. (1976) Programmed Instruction for Literacy Workers. Tehran, Iran: Hutton Educational Publications, Ltd..

TOEFL: Test and Score Data Summary. (1997) Princeton, NJ: Educational Testing Services

Triandis, H. C., Bontempo, R., Villareal, M.J., Asai, M., \& Lucca N. (1988). Individualism and collectivism: Cross-cultural perspectives on self-ingroup relationships. Journal of Personality and Social Psychology, 54, 323-338.

Weinstein, N. D. (1984) Why it won't happen to me: Perceptions of risk factors and susceptibility. Health Psychology, 3. 431-457.

Weishert, R. A. , \& Wells, L. E. (1996) . Rural crime and justice: Implications for theory and research. Crime \& Delinquency, 42, 379-397.

White, M. I. \& Barnet, S. (1995) Comparing cultures: Readings on contemporary Japan for American writers. Boston: St. Martin's Press .

White, M. (1995) . Japanese education: How do they do it? In White, M.I. and Barnet, S. (Ed.) Comparing cultures: Readings on contemporary Japan for American writers (pp. 95-108). Boston: St. Martin's Press .

Wigglesworth, P. G. (1992) . Lessons on ancient China for LEP students. (ERIC Document Reproduction Service, ED 348 861).

Wright C. \& Conroy, C. (1988) . Preparing CBI print-based support material: an information/instructional design perspective . Distance Education, 9, 84-94. 


\section{Appendix A}

Questions for focus group

The interview with the focus group began with an explanation of my research for a doctorate degree at West Virginia University. I acquainted the students with the topic of my dissertation. Then I explained the conditions for their participation:

1. Participation must be voluntary.

2. There would be no effect on their grades or academic careers if they participated or did not participate. The participants were:

M.S.- a Japanese female, 20 years old, an upperclassman

J.S.- an American male, 27 years old, Japanese Studies major, upperclassman

T.T.- an American female, 22 years old, Japanese Studies major, upperclassman

Y.S.- a Japanese male, 24 years old, an upperclassman

R.U.- a Japanese male, 19 years old, a freshman

R.S.- a Japanese female, 20 years old, a freshman

T.I.- a Japanese male, 22 years old, an upperclassman

The students were asked:

1. What did you think about your safety in the US before you came here?

2. Did your ideas change? If so, in what ways? When did your perceptions of safety change?

3. Have you personally experienced being the victim of crime in the US?

4. Do you know anyone who has personally experienced being the victim of crime in the US?

5. What do you think Japanese students need to know about safety when they come to the US?

6. Look at the 10 objectives I have developed. Do you agree that they are important to teach? What other suggestions do you have for objectives?

7. Do you read manga? Do you think a manga is a good way to teach students?

8. When I divide the group at random, I will separate out males/females, rural/urban hometowns, first time in US/previous experiences in the US. Can you think of other factors that need to be considered? 
Appendix B: The Comic Book

\section{The Adventures of}

\section{Kenji and Koji}

by: Susan Walsh

Illustrated by: Bill Leaseburg

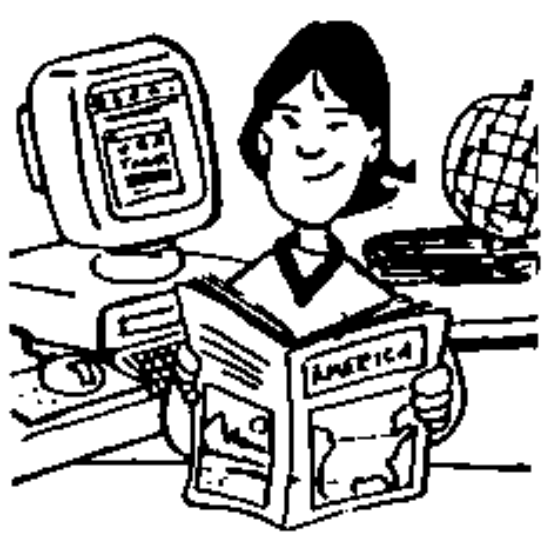

Kenji is a Japanese freshman who is going to sludy in the US. Ha is a careful person who learns all he can about this new country.

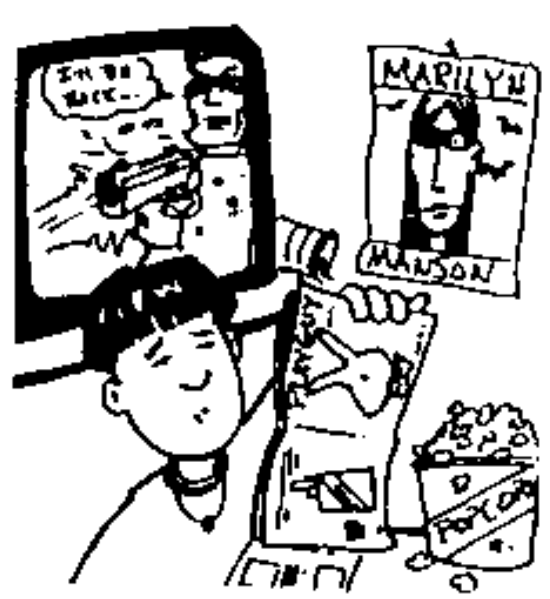

Koji is also a freshman who will go to the US. However, he thinks he knows that country already from TV and the movies. 


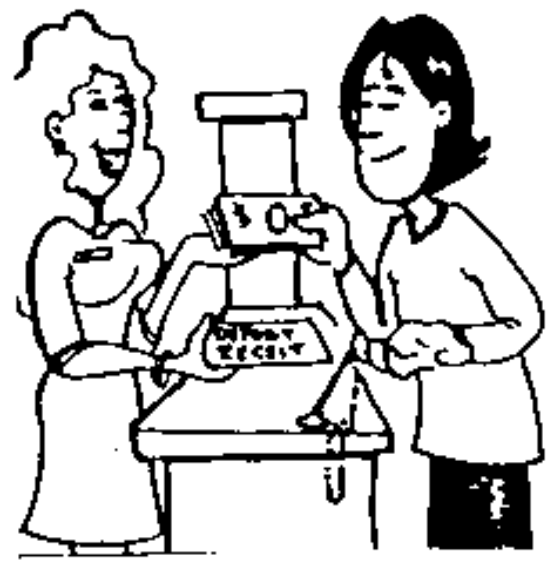

Kenji puts most of his money in a checking account at the bank. He carries only a small emount of money, and he knows how to use it.

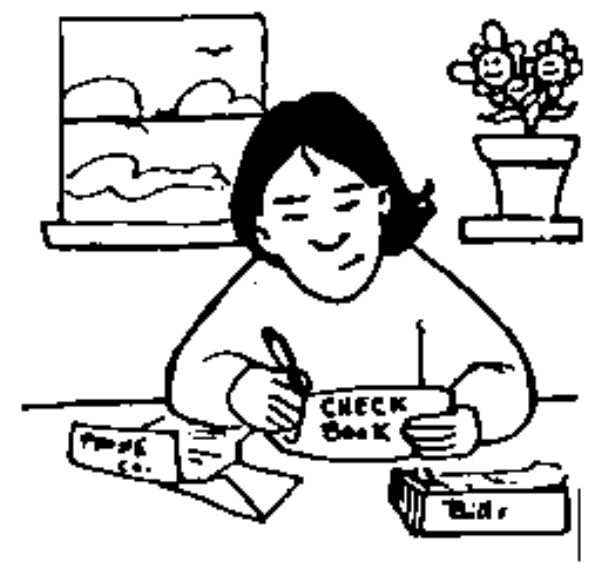

Kenji pays his bills with checks.

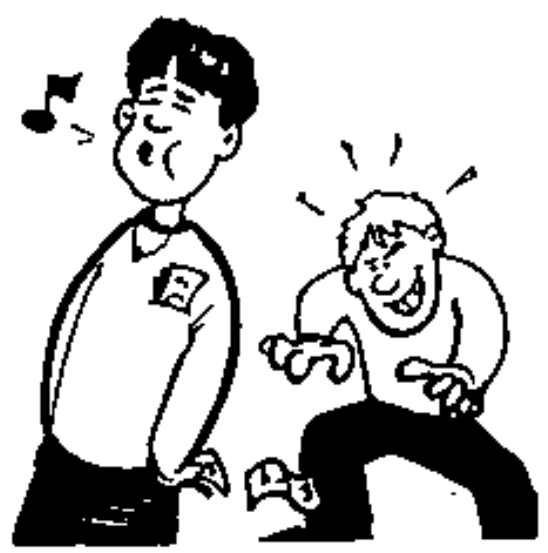

Koji carries large amounts of cash. He is careless and does not know how to give the correct change.

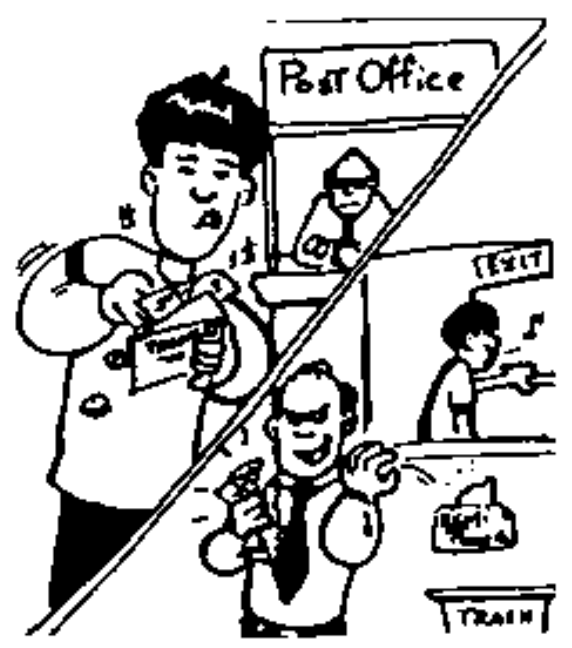

Koji sends cesh through the mail; it is stolen, so he must pay again. 


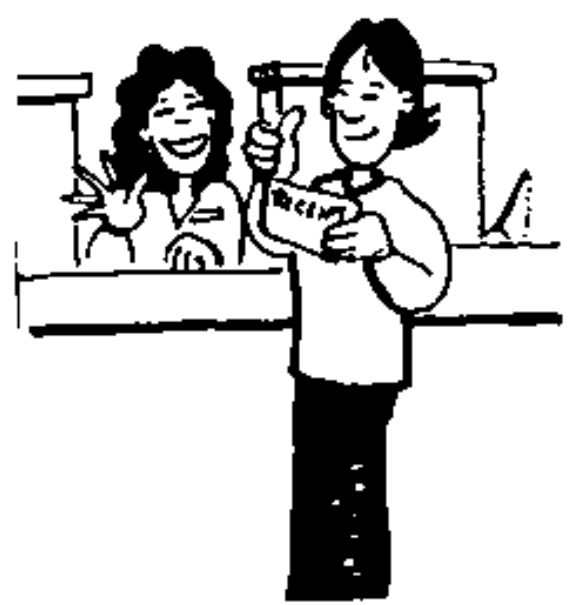

Kenji checks receipts carefully and keeps them in a safe place.

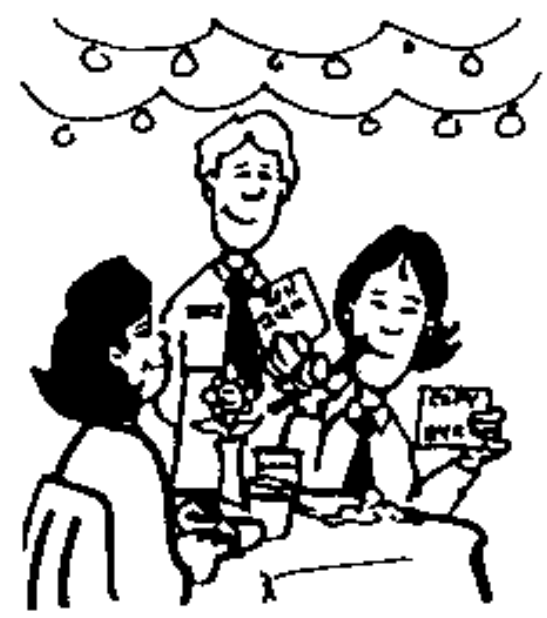

Kenjt checks ell bills before signing them; he keeps his copy.

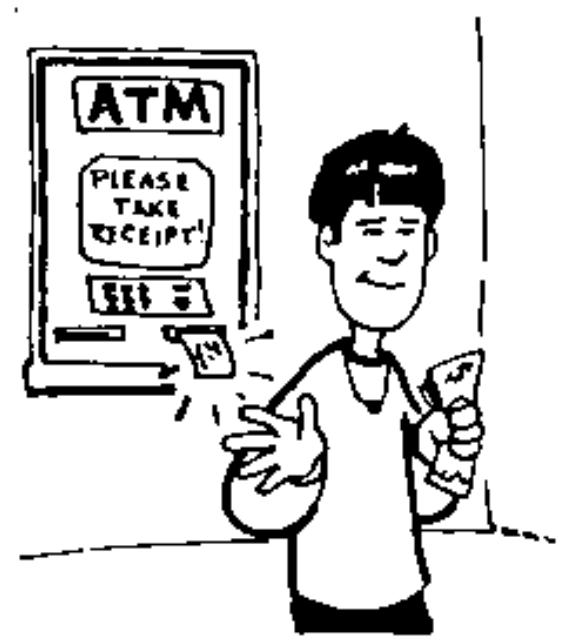

Koji does not look at his receipts. If the bank makes a mistake, he must pay for it.

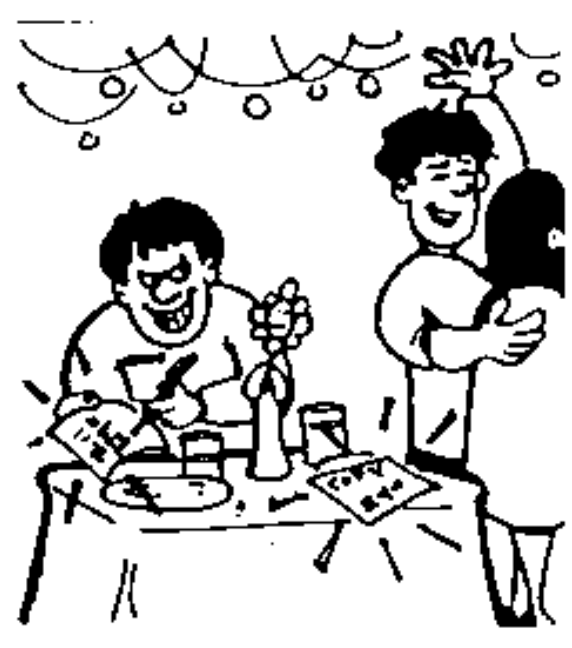

Koji does not read the bills, so he does nol know if someone changes it. 


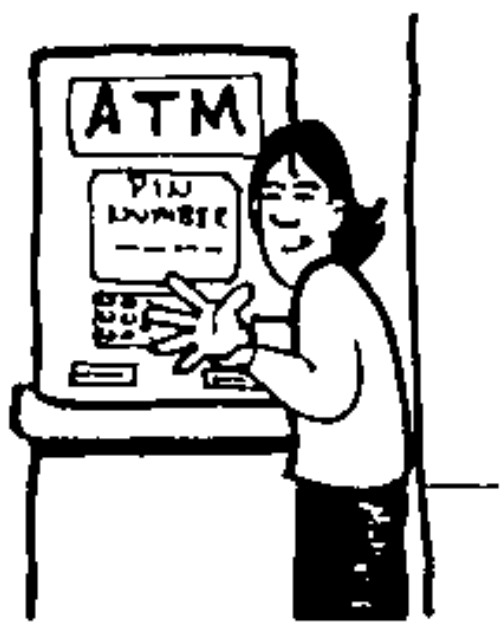

Kenji protects his PIN (Personal Identification Number) and credit card numbers.

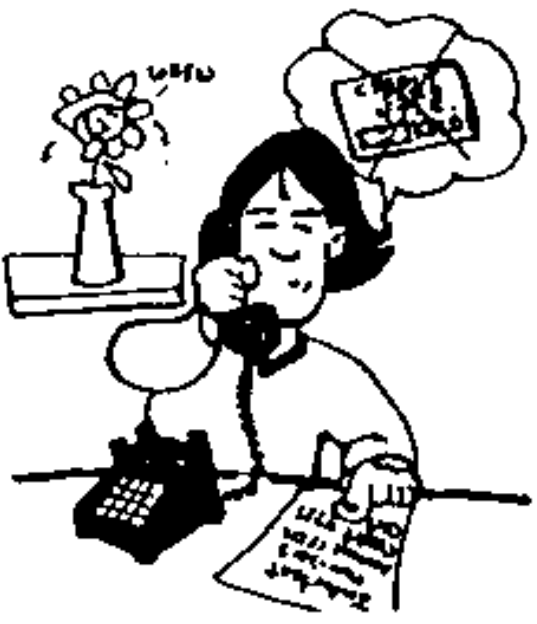

Kenji keeps a list of his credit card numbers, passport number, and checking account number. He keeps the list in a safe place, not in his wallel.

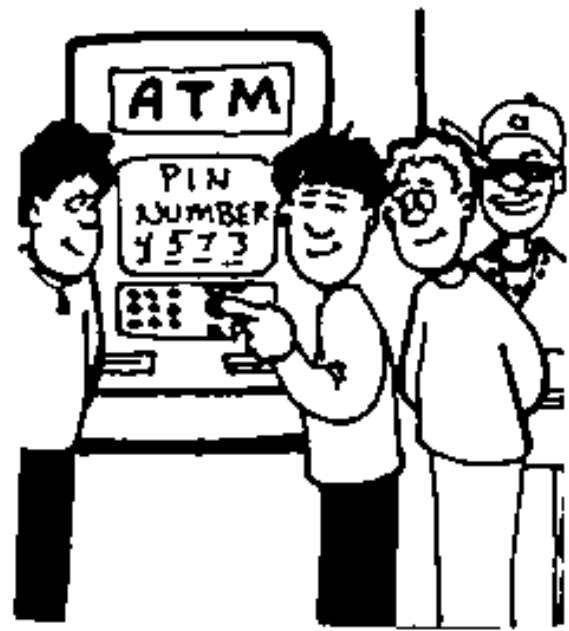

Koji is careless about his PIN.

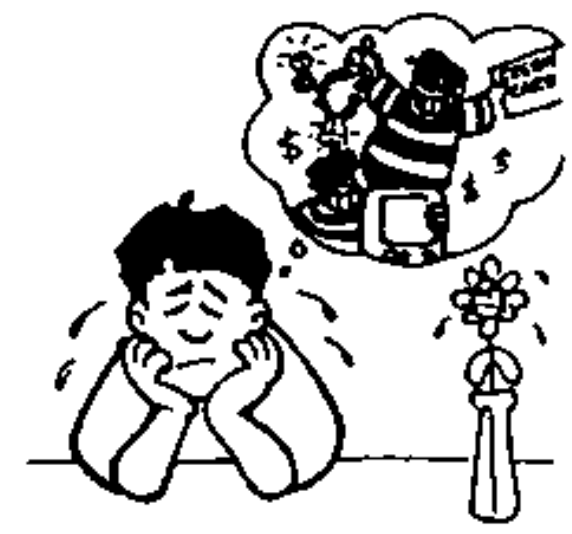

Koji does not have a list of important numbers. When his wallet is lost, he can't cancel his credit cards. 


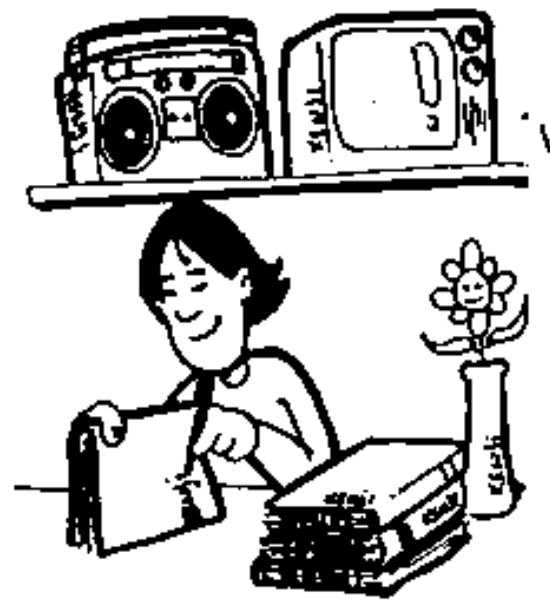

Kenij takes care of his property. he writes his name on his books. TV, games, and other lhings.

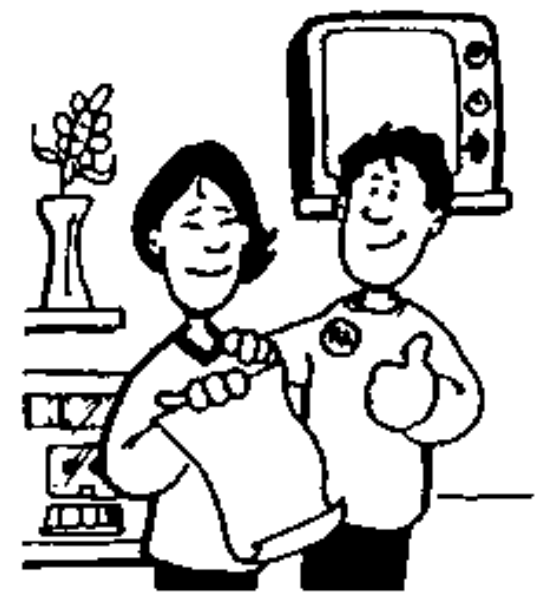

Kenji makes a llst of the serial numbers of his property and gives the list to his RA.

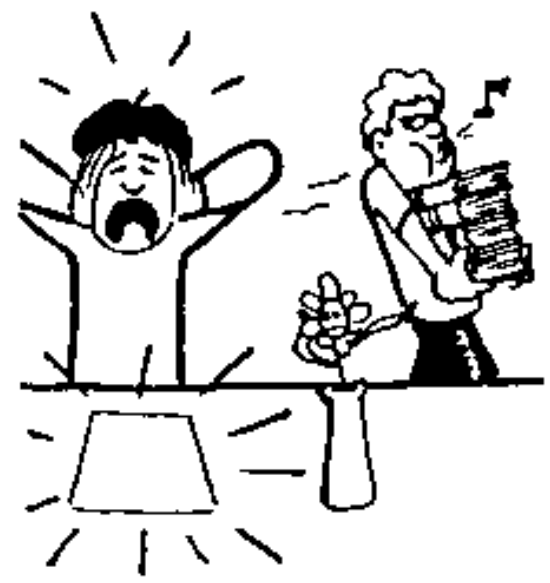

Koji doos not mark anything; It's too much trouble. Later, he can't prove that his things are his.

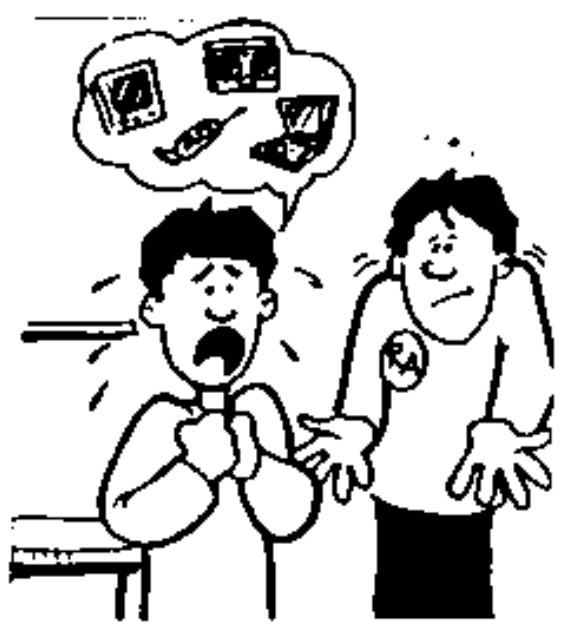

Koji does not make a list. When his TV is stolen, he cannot prove that the one in his neighbor's room Is his. 


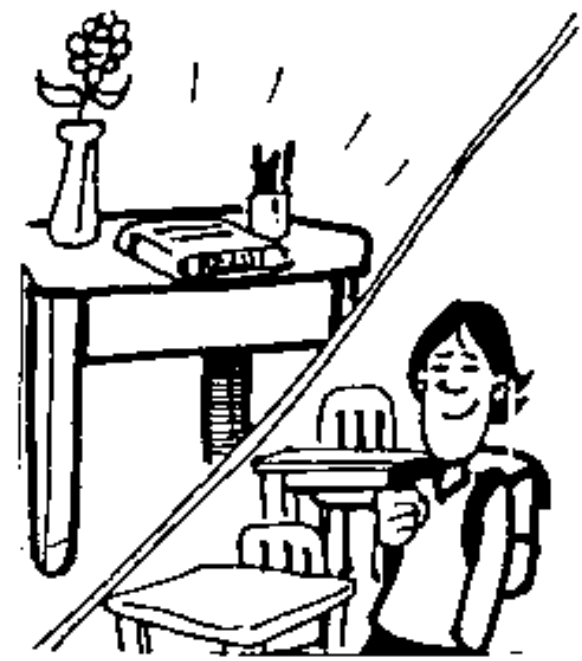

Kenji never leaves his valuables Iying around. He carries his book bag when he leaves a class. room.

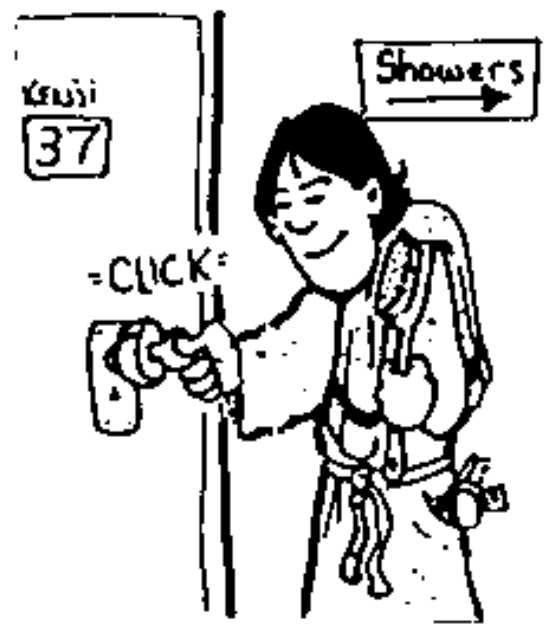

Kenji amways locks his door with the key, even when he goes to the restroom.

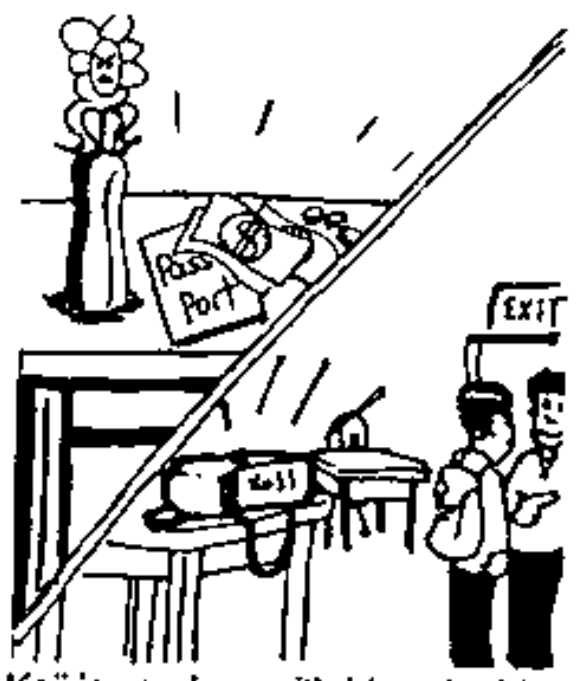

Koji is careless with his valuables. He makes it easy for thieves to help themselves.

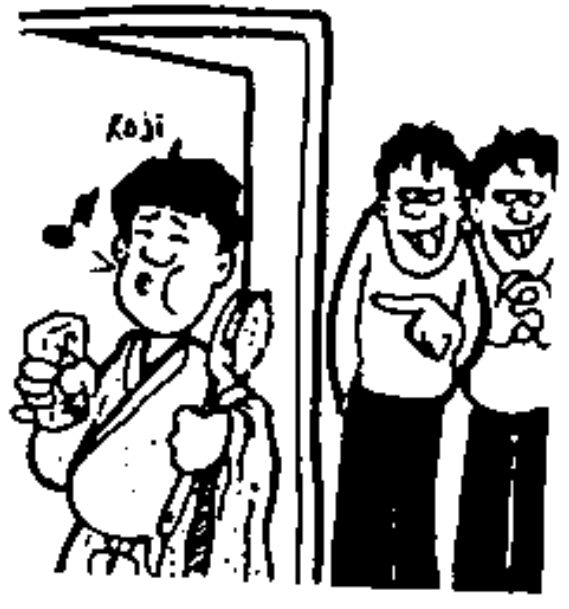

Koji doesn't lock his door and he invites in some unwelcome visitors. 


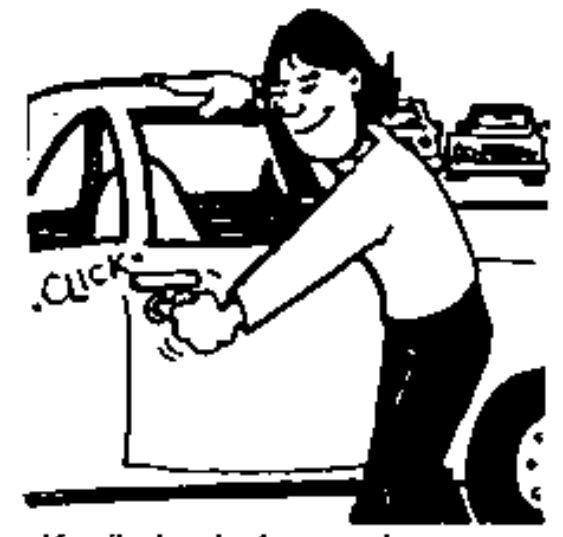

Kenji also kocks car doors.

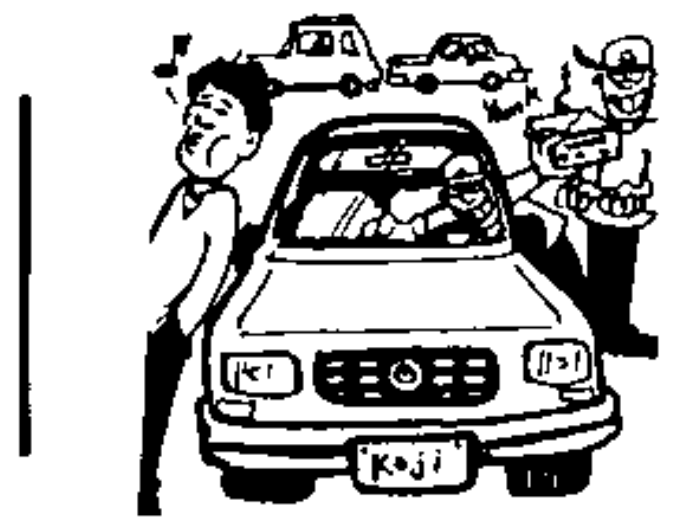

Koji does not think it is necessary to lock the car.

\section{True or False?}

\section{Quiz}

1. The safest way to keep money in the US is in a checking account at a bank.

2. It is safe to pay bills with cash sent through the mail.

3. You should always read the receipts when you get them from the bank.

4. You do not need to check credit card bills before you sign them

5. It is safe to share your Personal Identification Number with friends.

6. Writing your name on your belongings helps to get them back if they are stolen.

7. If your credit card is stolen, there is nothing you can do to stop thieves from making you pay for their purchases.

8. You should always lock your door by pushing the button. 


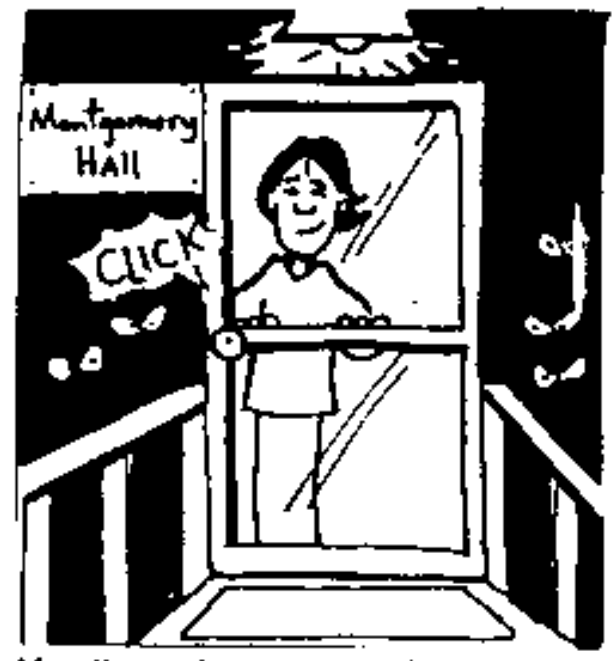

Kenji makes sure the outside doors of the residence halls close and lock after him.

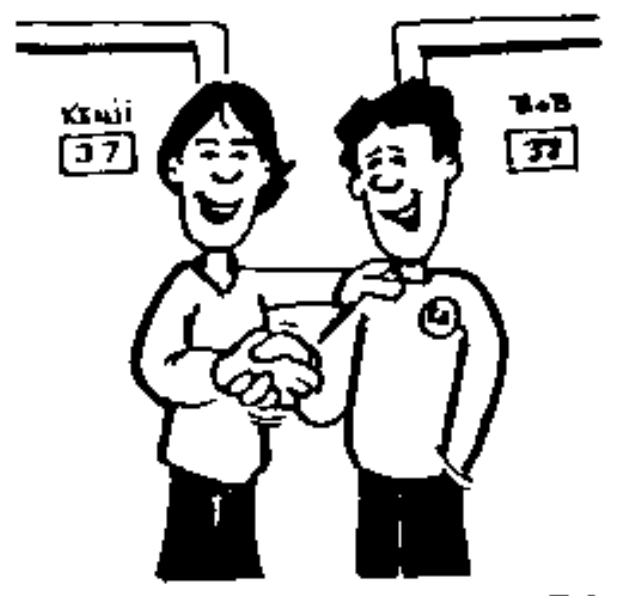

Kenji knows how to reach his RA.

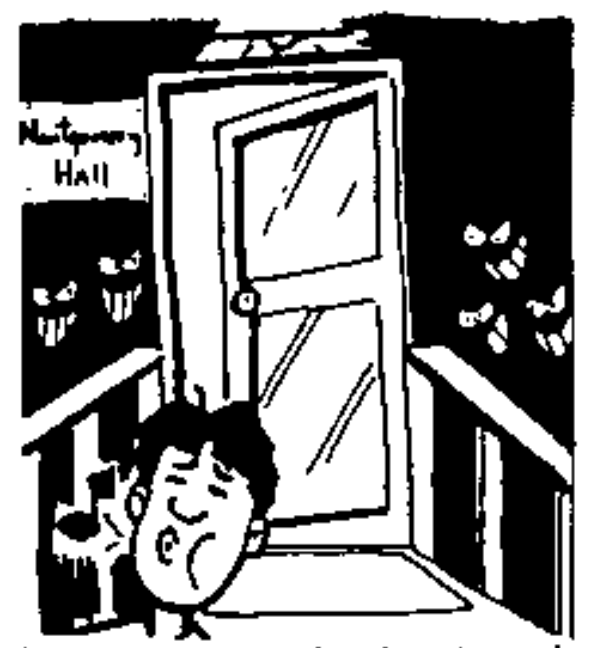

Koji props open the door to make it easter for him to come and go; however, others can also come and gol

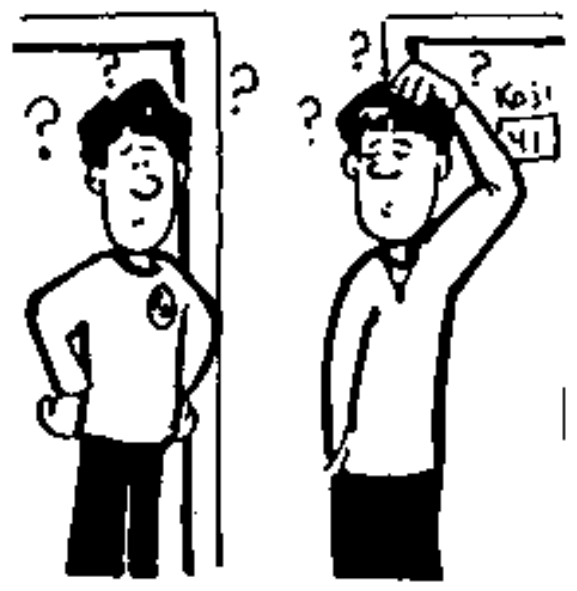

Koji does not know who his RA is. 


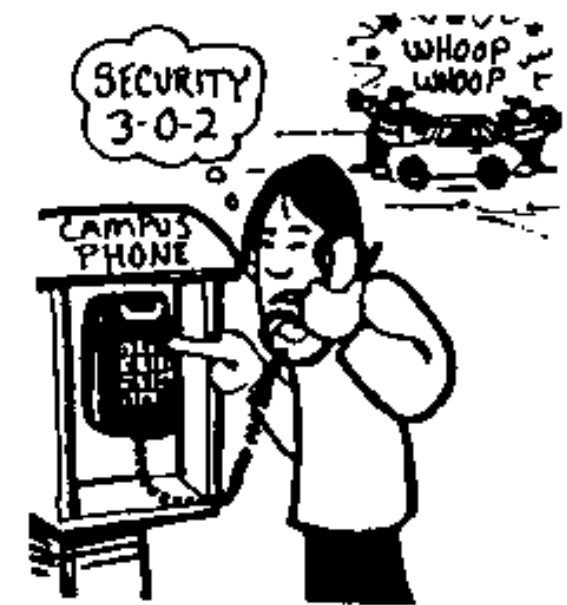

Ken]i knows how to call Security on cempus phones: 302.

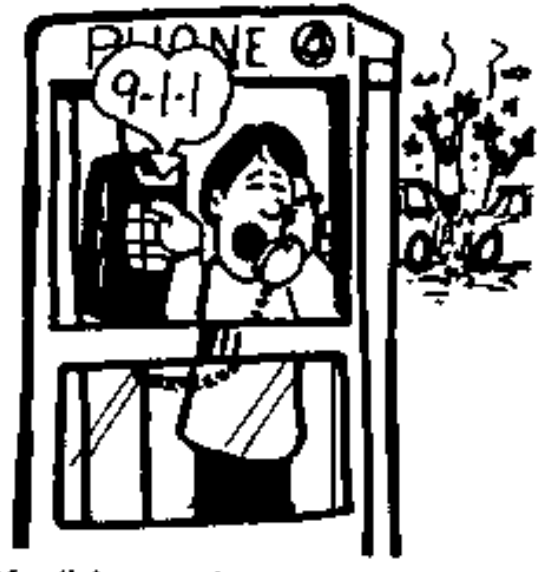

Kenji knows how to dial 911 for emergencies.

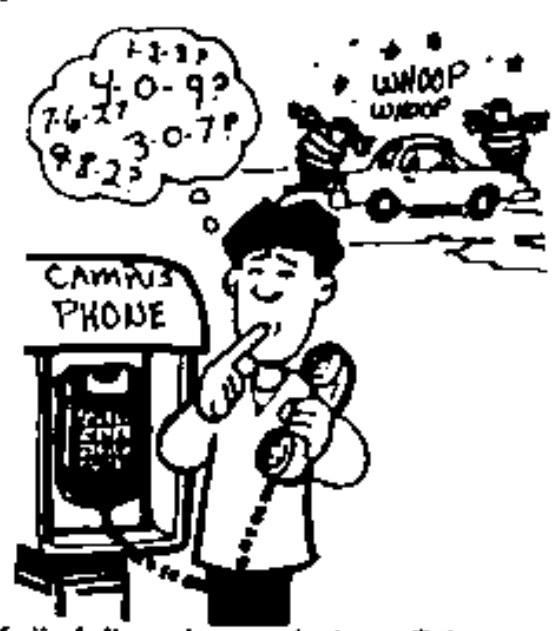

Koji fell asleep during Orientation. He does not know the number for campus security.

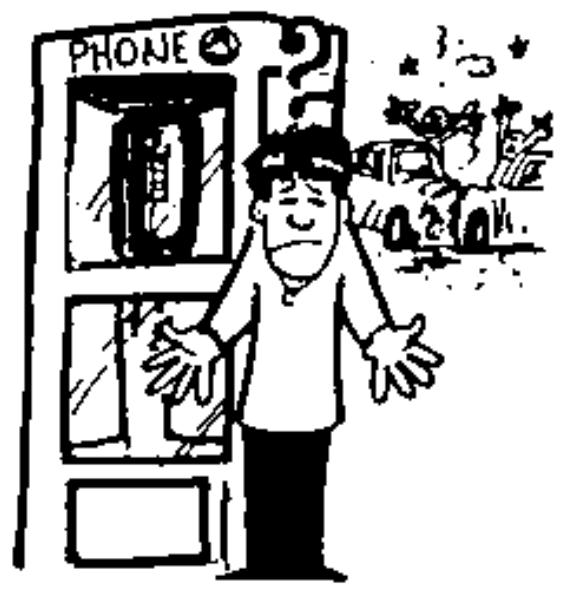

Koji forgets the number to call for emergencies. 


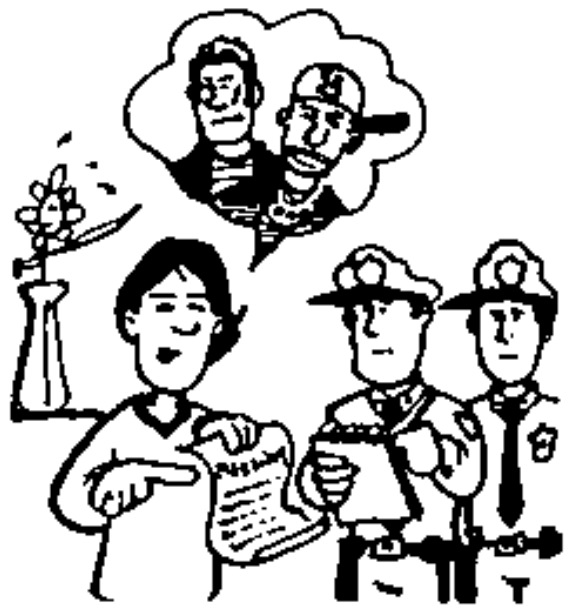

Kenji knows the police cannot help you if you don't give them information.

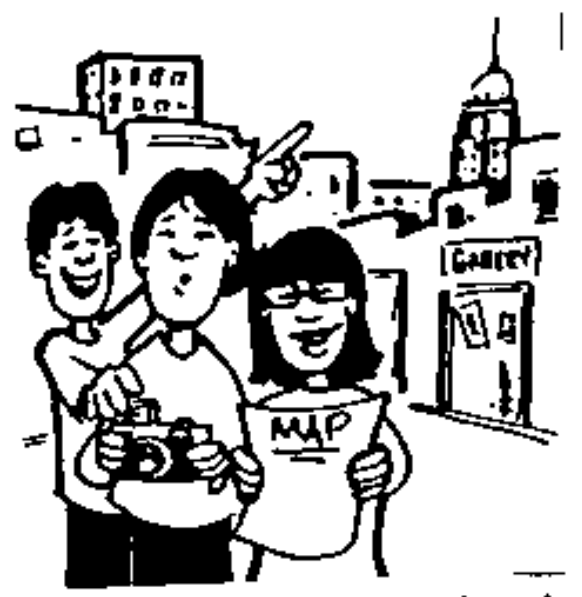

Kenji stays in groups when he visits large cities; he walks in safe, well-lit places.

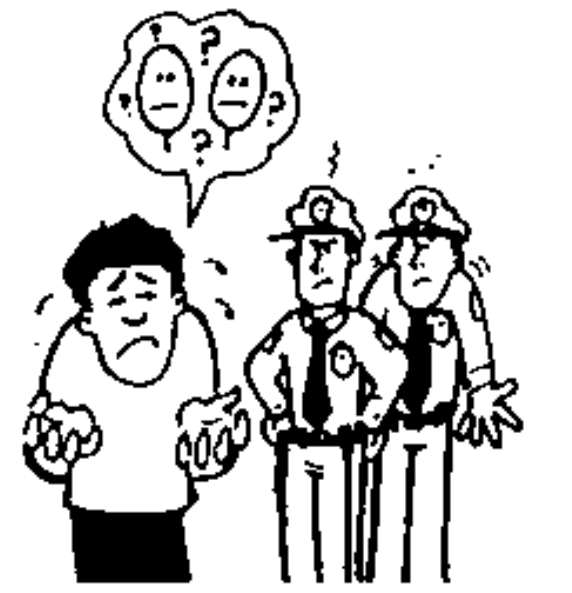

Koli cannot otwo the police any information. Ho gote angry because they cannot help rim.

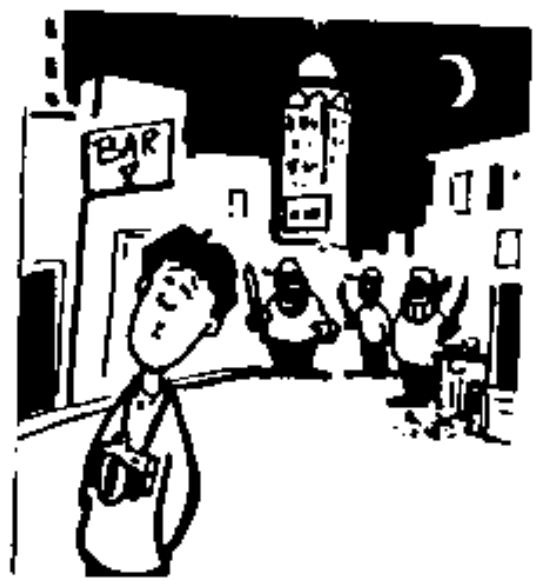

Kof pow 10 dangerous places alone. 


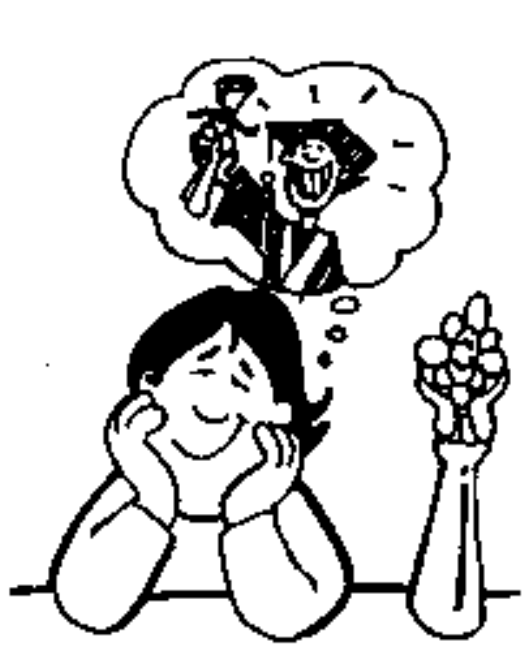

Kenf has a heppy experience in the US.

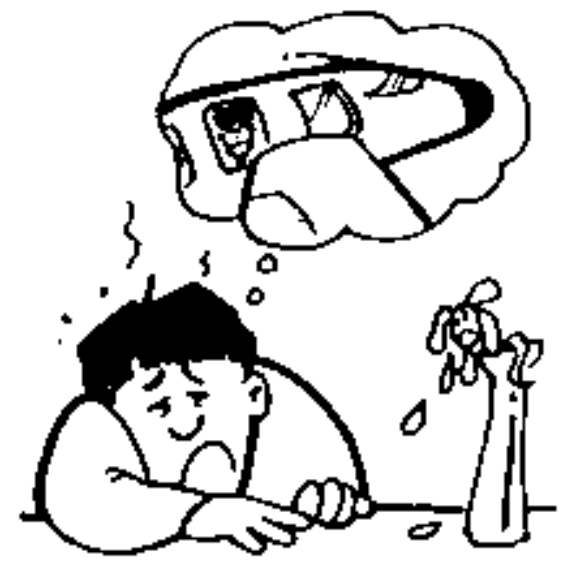

Koli has en untappy experience and wants to relum home. 


\section{Remember!!}

1. Do not carry large amounts of money on you. The safest way to keep money is in a checking account.

2. Do not send cash through the mail. Use a check or money order (which you can buy at the Post Office).

3. Do not be careless with your money; do not ask other people to count your money for you.

4. Always check receipts and bills. Keep your copies in a safe place.

5. Do not let anyone know your PIN.

6. Make a list of your important numbers (credit cards, passport, bank account) and give the list to your RA.

7. Put your name on all your belongings and keep a list of serial numbers.

8. Do not leave your valuables lying around.

9. ALWAYS lock your room door, car doors, and outside doors.

10. Your RA lives in your residence hall, The number for campus Security is 302, from any campus phone. The number for general emergencies is 911.

11. The police can't help you if you cannot identity your belongings, or it you lose cash.

12. Stay in groups in cities and walk in safe places.

\section{If you are careful, you can have a wonderful experience as a student in the US!}




\section{Appendix C: SPACCI}

\section{Safety Practices on American College Campuses Inventory}

Part 1. Information about you.

1. Are you a male? or a female? (check one)

2. How old are you?

3. Is your hometown in Japan urban or rural? urban _rural (check one)

4. Have you ever lived in the US before ?

5. Are you transferring to S-TU? yes no (check one)

If you answered "yes", from what college are you transferring?

$* * * * * * * * * * * * * * * * * * * * * * * * * * * * * * * * * * * * * * * * * * * * * * * * * * * * * * * * * * * * * * * * * * * * * * * * * * *$

Part 2. Circle the answer that describes how you will behave in the US.

1. Will you carry a lot of money on you in the US?

definitely yes yes no definitely no

2. Will you send cash through the mail to pay your bills?

definitely yes yes no definitely no

3.Will you hide your money or keep it securely in your wallet?

definitely yes yes no definitely no

4. At a store, will you ask someone else to count out your correct change?

definitely yes yes no definitely no

5. Will you look at credit card bills before signing them?

definitely yes yes no definitely no

6 . Will you check the receipts you get at the bank or ATM machine?

definitely yes yes no definitely no

7. Will you let other people see your PIN?

definitely yes yes no definitely no

8. Will you make a list of credit card numbers and keep it in a safe place?

definitely yes yes no definitely no

9. Will you put your name on your books in a place that others can see it?

definitely yes yes no definitely no

10 . Will you put your name on all your belongings?

definitely yes yes no definitely no

11. Will you make a list of the makes and serial numbers of your belongings

(TV, video games, etc.) and give this list to your RA?

definitely yes yes no definitely no

12. Will you lock your door with the key when you go to class?

definitely yes yes no definitely no

13. Will you lock your door with the key when you do the laundry?

definitely yes yes no definitely no

14. Will you leave your door unlocked when you visit a friend's room?

$\begin{array}{llll}\text { definitely yes yes no definitely no } & \end{array}$

15. Will you leave your door unlocked when you go to the restroom? 
definitely yes yes no definitely no 16. Will you lock car doors when you leave?

definitely yes yes no definitely no

17. Will you leave your possessions where someone might take them?

definitely yes yes no definitely no

18. Will you leave your book bag in an empty classroom?

definitely yes yes no definitely no

19. Will you be able to find where your RA lives?

definitely yes yes no definitely no

20. Will you be able to recognize your RA's face?

definitely yes yes no definitely no

21. Do you know the number to dial for campus Security?

definitely yes yes no definitely no

22. Do you know the number to dial for emergencies such as for the

police, fire department, or ambulance?

definitely yes yes no definitely no

23. Do you think the police in the US can do the same things for you as they do in Japan?

definitely yes yes no definitely no

24. If you became a victim of a crime, could you describe the situation to the police?

definitely yes yes no definitely no

25 . Will you travel by yourself in unknown cities?

definitely yes yes no definitely no

$* * * * * * * * * * * * * * * * * * * * * * * * * * * * * * * * * * * * * * * * * * * * * * * * * * * * * * * * * * * * * * * * * * * * * * * *$

Part 3. Please write the answers to the following questions.

1. What is the name of your RA?

2. Where does your RA live?

3. What is the maximum amount of money you would feel comfortable carrying in your wallet? \$

4. What is the maximum amount of money you would feel comfortable keeping in your dormitory room? \$

5. What is the number to call campus Security?

6. What is the number to report an emergency?

7. To lock your room when you leave, you just push the button in. _ True __ False (check one)

8. Do you know how to write checks? ___ yes __ no (check one)

9. Do you have any credit cards? __yes __ no (check one)

10. What can this university do to make you feel safe here? 


\section{Appendix D \\ Comparison of Objectives and Inventory Questions}

There were four main concepts about personal safety that were stressed. Each concept led to the development of specific objectives. In this appendix, the concepts are listed first, followed by the objectives of the inventory and then by the inventory questions which address the objective (set off by bullets). The Roman numerals indicate the part of the SPACCI, while the Arabic numbers refer to the number of the question. (Thus, II.1 means the first question in Part 2 of the inventory.)

1. In the US. cash is not used as frequently as it is in Japan because there are dangers in carrying large sums of cash.

a. Students should not carry large sums of money on their persons.

- II.1 Will you carry a lot of cash on you in the US?

- III.3 What is the maximum amount of money you would feel comfortable carrying in your wallet?

- III.4 What is the maximum amount of money you would feel comfortable keeping in your dormitory room?

- III.8. Do you know how to write checks?

b. They should not send cash through the mail.

- II.2 Will you send cash through the mail to pay your bills?

c. They should not be conspicuous in carrying money.

- II.3 Will you hide your money or keep it securely in your wallet?

d. They must learn to use the currency correctly.

- II.4 At a store, will you ask someone else to count out your correct change?

2. Non-cash sources of money (checks, credit cards, bank or ATM cards) are convenient but they need to be used carefully.

a. Students should always check bills before they sign them, check receipts when they receive them, and keep all receipts because their card number may be on them.

- II.5 Will you look at credit card bills before signing them ?

- II.6 Will you check the receipts you get at the bank or ATM machine?

- III.9 Do you have any credit cards?

b. Students should protect the security of their Personal Identification Number (PIN).

- II.7 Will you let other people see your PIN? 
c. They should keep a list of their credit card in a safe place.

- II.8 Will you make a list of credit card numbers and keep it in a safe place?

3. Personal possessions need to be protected.

a. Students should identify all their possessions by putting their names on books, appliances, games, and all other possessions.

- II.9 Will you put your name on your books in a place that others can see it?

- II.10 Will you put your name on all your belongings?

b. They should record the serial numbers of their valuables and give the list to their Residence Assistant (RA).

- II.11 Will you make a list of the makes and serial numbers of your belongings (TV, video games, VCR, etc.) and give this list to your RA?

c. They should always lock their room door, their car doors, and the door to their residence hall.

- II.12 Will you lock your door with the key when you go to class?

- II.13 Will you lock your door with the key when you do the laundry?

- II.14 Will you lock your door with the key when you go to a friend's room?

- II.15 Will you lock your door with the key when you go to the restroom?

- II.16 Will you lock car doors when you leave?

- III.7 True or false? To lock your room when you leave, you just push the button in.

d. Students should not leave their valuables where they could be taken.

- II.17 Will you leave your possessions where someone might take them?

- II.18 Will you leave your book bag in an empty class room?

4. Protection and help are available if the students are in trouble, but they are responsible for assisting the authorities.

a. Students need to know how to reach their RA, campus security, and the police.

- II.19 Will you be able to find where your RA lives?

- II.20 Will you be able to recognize your RA's face?

- II.21 Do you know the number to dial for campus Security?

- II.22 Do you know the number to dial for emergencies such as for the police, fire department, or ambulance?

- III. 1 What is the name of your RA?

- III.2 Where does your RA live?

- III. 5 What is the number to call campus Security?

- III.6 What is the number to report an emergency? 
b. The police cannot help if the students are unable to provide identifying numbers, descriptions, etc. Police in the US do not have as much discretionary power in apprehending criminals as they do in Japan.

- II.23 Do you think the police in the US can do the same things for you as they do in Japan?

- II.24 If you became a victim of a crime, could you describe the situation to the police? people.

c. An important factor in safety, especially in strange places, is to be with other

- II.25 Will you travel by yourself in unknown cities? 
Appendix E

Sample Letter to Students

\section{Dear Students,}

I am an instructor of ESL at Salem-Teikyo University. I am also working on a doctorate at West Virginia University in Morgantown. I would like to ask you to take a few minutes to answer the questions in the following inventory. The information you provide will help Salem-Teikyo University provide safety instruction to the incoming freshmen students of the future. Your participation in this project is entirely voluntary, and it will not affect your grades or standing at this university in any way. The information will be kept confidential. It will be used for research in my doctorate and it will help us prepare for new students. Thank you very much for your help in this project.

Sincerely, 
Appendix F

Results of the SPACCI

(Safe Practices on American College Campuses Inventory)

Method of scoring: every question had a "safest" answer. This answer was given four points. The next safest answer was three points, the next, two points, and the least safe answer was one point. There were twenty-five questions, so every student had the possibility of scoring 100 points for the total score. Student numbers were assigned for identification of tests only. *Some students did not complete the inventories and their scores were not used in the data analysis.

\begin{tabular}{|c|c|c|c|c|c|c|c|c|}
\hline \multirow{2}{*}{$\begin{array}{l}\text { StudentID } \\
\text { number }\end{array}$} & \multicolumn{8}{|c|}{ Control Group } \\
\hline & \multirow{2}{*}{$\frac{\text { Gender }}{\mathrm{M}}$} & \multirow{2}{*}{ Age } & \multicolumn{2}{|c|}{ Hometown } & \multirow[t]{2}{*}{ Pre } & \multirow{2}{*}{$\frac{\text { Post }}{73}$} & \multicolumn{2}{|c|}{ Post/post } \\
\hline & & & 18 & $\mathrm{R}$ & & & 95 & 94 \\
\hline 941 & M & & 18 & $\mathrm{R}$ & & 75 & 93 & 87 \\
\hline 946 & M & & 18 & $\mathrm{R}$ & & 68 & 73 & 77 \\
\hline 947 & F & & 20 & $\mathrm{R}$ & & 73 & 94 & * \\
\hline 954 & $\mathrm{~F}$ & & 21 & $\mathrm{U}$ & & 84 & 92 & 97 \\
\hline 955 & $\mathrm{M}$ & & 19 & $\mathrm{U}$ & & 69 & 73 & 69 \\
\hline 956 & $\mathrm{~F}$ & & 18 & $\mathrm{U}$ & & 77 & 90 & 88 \\
\hline 957 & M & & 19 & $\mathrm{U}$ & & 67 & 92 & 81 \\
\hline 958 & $\mathrm{~F}$ & & 18 & $\mathrm{R}$ & & 82 & 96 & 92 \\
\hline 963 & $\mathrm{M}$ & & 19 & $\mathrm{U}$ & & 73 & 87 & * \\
\hline 967 & $\mathrm{M}$ & & 18 & U & & 68 & 73 & 73 \\
\hline 968 & $\mathrm{~F}$ & & 20 & U & & 74 & 90 & 94 \\
\hline 969 & M & & 18 & $\mathrm{R}$ & & 67 & 96 & 83 \\
\hline 970 & $\mathrm{~F}$ & & 20 & $\mathrm{U}$ & & 83 & 94 & 94 \\
\hline 971 & $\mathrm{M}$ & & 19 & $\mathrm{U}$ & & 83 & 93 & 95 \\
\hline 972 & M & & 18 & U & & 73 & 73 & 71 \\
\hline 973 & M & & 18 & $\mathrm{R}$ & & 71 & 92 & 77 \\
\hline 976 & M & & 18 & $\mathrm{R}$ & & 81 & 95 & 93 \\
\hline 982 & $\mathrm{M}$ & & 21 & $\mathrm{U}$ & & 82 & 95 & 100 \\
\hline Mean score & & & & & 88 & 86.2 & & \\
\hline
\end{tabular}

( $\mathrm{n}=19$ for post test, 17 for post post test) 


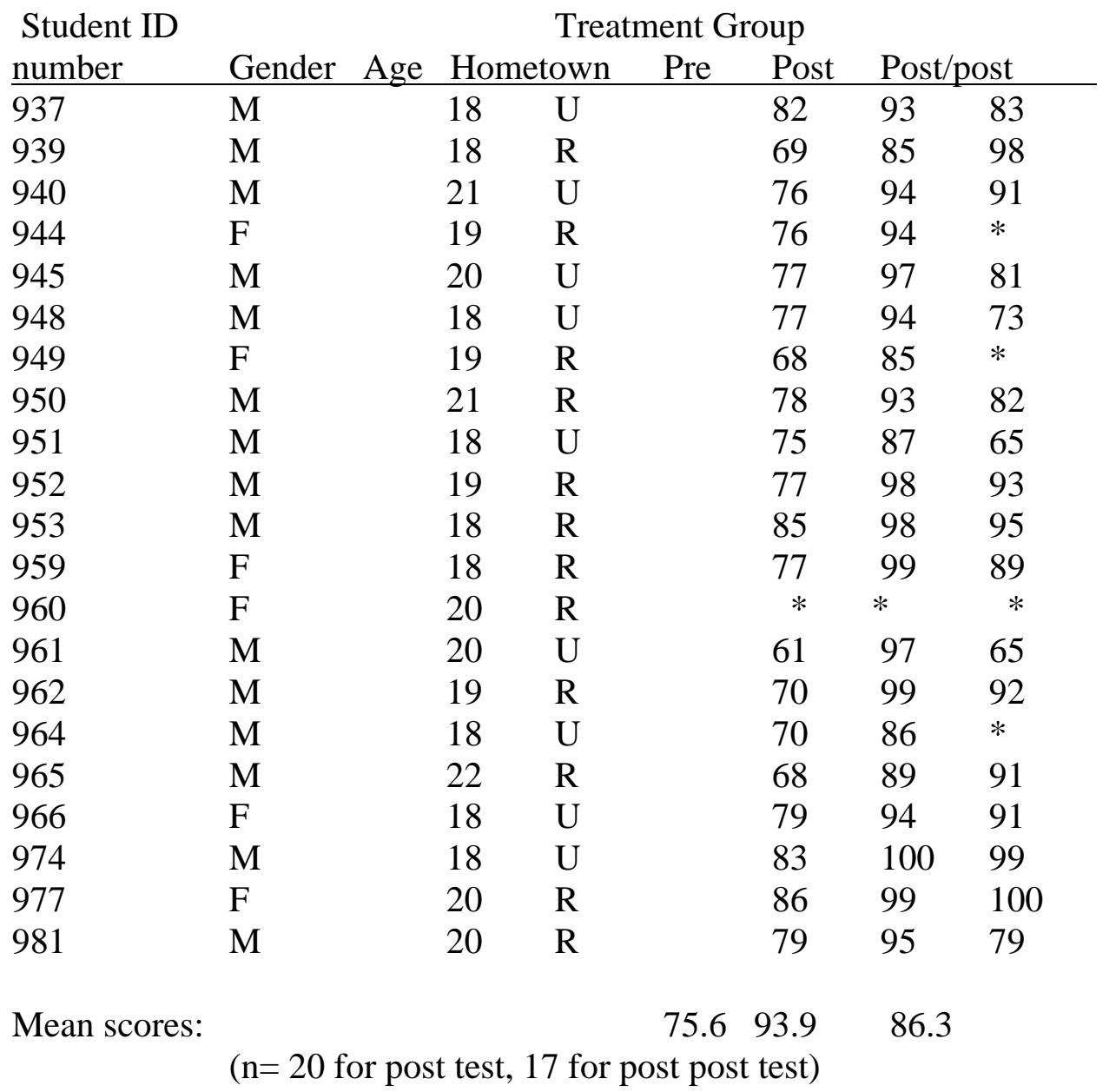

- Indicates incomplete tests 
Curriculum Vitae

Susan F. Walsh

\section{EDUCATION}

B.A., University of Delaware, 1964

Major: International Relations

M.A.T., Fairleigh Dickinson University, 1972

Major: Social Studies

A.D.N., Fairmont State University, 1990

R.N. Licensure, June 1990

Ed. D., West Virginia University, 1999

Major: Curriculum and Instruction

Specialization: Social Studies

\section{WORK EXPERIENCE}

1968-1970 Ranong Girls' School, Ranong, Thailand

Peace Corps Volunteer

Taught English as a Second Language, $8^{\text {th }}$ and $9^{\text {th }}$ grades

1970-1971 Saint Paul's Elementary School, Burlington, N.J.

Taught science and geography, $7^{\text {th }}$ and $8^{\text {th }}$ grades

1971-1972 Paramus Catholic Girls' School, Paramus, N.J.

Taught $10^{\text {th }}$ and $11^{\text {th }}$ grade American History

1990 R.N., United Hospital Center, Clarksburg, W.V.

R.N., Clarksburg Continuous Care Center, Clarksburg, W.V.

1991- present Salem-Teikyo University, Salem, W.V.

Instructor of English Studies (E.S.L.) 